\title{
LA CORONA EN LA DIPLOMACIA (PÚBLICA) ESPAก̃OLA
}

\section{The Spanish Crown in (public) diplomacy}

\author{
Alberto Priego \\ Universidad Pontificia Comillas \\ Departamento de Relaciones Internacionales \\ apriego@chs.upcomillas.es
}

La institución diplomática puede dividirse entre la tradicional y la no tradicional. Mientras que la primera se remonta varios siglos atrás la no tradicional es un fenómeno reciente. Fue después de la Segunda Guerra Mundial cuando los Estados Unidos comenzaron a proyectar Resumen sus valores con el fin de convencer a las sociedades enemigas. Hoy todos los Estados hacen uso de la diplomacia pública para alcanzar sus fines. Sin embargo, muchos autores como Berridge han calificado a la diplomacia pública como mera propaganda. Para ganar credibilidad se ha buscado implicar en la diplomacia pública a instituciones del estado tales como la monarquía. El caso de España no es una excepción. La Casa Real juega un papel muy destacado en la diplomacia, tanto tradicional como pública. El principal motivo es que tiene tres valores que no tienen ninguna otra institución: neutralidad política (Rupérez, 2014)1, continuidad (Turner)² e identificación plena con España. Por ello la monarquía española es un actor muy apropiado para la puesta en práctica de la diplomacia pública.

Diplomacia tradicional, diplomacia no-tradicional, diplomacia pública, Corona

Diplomacy, Public Diplomacy, Crown, Head of State, National Branding

Q Key words 
The Diplomatic Institution can be divided into traditional and non-traditional diplomacy. While traditional diplomacy dates back several centuries, non-traditional diplomacy is a relative newcomer, with the USA beginning to project their own values in order to convince enemy societies after the end of World War II. Today all states make use of public diplomacy to achieve their aims in foreign policy; however, many authors (Berridge, 2010) have described public diplomacy as mere propaganda. Due to this lack of credibility, monarchies have assumed increasingly more importance in the area of public diplomacy. Spain is no exception. The Spanish Royal Family has played, and continues to play, a fundamental role in both traditional and public diplomacy. There are three key values which the Spanish Monarchy enjoys in respect of the Spanish political system and these are: its political neutrality (Rupérez, 2014), its continuity (Turner) and its full identification with Spain. Given these crucial values, the Spanish Monarchy is a more than suitable actor for the implementation of public diplomacy.

\section{Introducción}

La institución diplomática ha estado tan vinculada a las monarquías que Montesquieu llegó a decir que "los embajadores encarnan la palabra del príncipe que los envía" (Gómez Mampaso \& Sáenz de Santamaría, 2001). En sus orígenes, los diplomáticos representaban directamente a los monarcas y precisamente por ser su representante gozaban de una serie de privilegios e inmunidades que, en cierto modo, hoy persisten. La mayor parte de las monarquías se han ido modernizando y constitucionalizando aunque en el plano formal siguen manteniendo formas que resultan arcaicas. En el campo de la diplomacia este fenómeno es mucho más acusado y en algunos países como el Reino Unido aún se mantienen fórmulas y expresiones propias de otro tiempo como "Embajador de su Majestad" aunque en realidad hoy el embajador ya no representa al soberano sino al Estado (Vilariño, 2007) en su conjunto.

No obstante, este proceso de constitucionalización ha llevado a los monarcas a perder protagonismo en la fase de la formulación de la política exterior pero, por el contrario, lo han incrementado en la puesta en práctica de la misma. Paralelamente a este fenómeno y como consecuencia de la transformación de la institución diplomática, las Coronas han emergido como instrumentos muy válidos para la diplomacia pública. La principal razón es que nadie representa tan fehacientemente la esencia misma del Estado como ellos. Por lo tanto, en aquellos Estados donde ha habido un proceso de constitucionalización de las monarquías, éstas han visto desplazada su actividad exterior al plano de la diplomacia (tradicional) configurándose como un instrumento muy valioso de diplomacia (no tradicional) pública.

En el caso de España, la Constitución de 1978 regula en detalle el papel del Rey en la diplomacia (tradicional). Al ostentar la Jefatura del Estado, el Rey de España sigue manteniendo una importante presencia en cuestiones formales de la política exterior como la manifestación del consentimiento o la acreditación de embajadores. Sin embargo, hay algunos aspectos de la diplomacia (no tradicional) pública que han sido asumidos por la Corona al poseer ésta unas características (neutralidad política (Elzinga, 2009), continuidad e identidad con el Estado) que no tiene ninguna otra institución y que, por tanto, la convierten en el actor óptimo para estas tareas.

Este artículo se organizará de la siguiente forma. En primer lugar, vamos a tratar de esclarecer algunos conceptos clave como diplomacia, política exterior o diplomacia pública y una vez definidos, trataremos de analizar cuál es el rol de la Corona de España tanto en la diplomacia 
tradicional $^{3}$ como en la no tradicional. Concluiremos analizando por qué creemos que la Corona es una institución óptima para el desarrollo de la diplomacia pública.

\section{Conceptos}

Existen muchas definiciones de diplomacia aunque -y quizás por ello- aún no se ha alcanzado un consenso sobre cuál de todas ellas es la mejor. Quizás quien mejor ha sabido recoger las diferentes sensibilidades ha sido Sir Peter Marshall. El diplomático británico parte de la hipótesis de que diplomacia es un concepto polisémico y por tanto mejor que buscar una definición, es más inteligente esclarecer cuales son los diferentes significados. Sir Peter Marshall destaca hasta seis significados diferentes de la palabra diplomacia.

a) En primer lugar, diplomacia podría ser entendida como el contenido propio de los asuntos internacionales. Esta concepción estaría más cercana al concepto Relaciones Internacionales que al de diplomacia.

b) En segundo lugar, diplomacia podría entenderse como la forma de comportarse en política exterior. En este sentido, la diplomacia sería la otra cara de la moneda de la guerra, entendiendo ésta como el punto álgido del conflicto y por contraposición la diplomacia como cooperación. Sin embargo, si partimos de la premisa de que la paz es conditio sine quanum para poder hablar de diplomacia, se podría decir que el punto álgido de la cooperación no sería la diplomacia sino la integración. En todo caso, estaríamos hablando de una forma de implementar la política exterior de un modo pacífico.

c) En tercer lugar, diplomacia puede ser asimilada a la negociación lo que conlleva dos implicaciones. Por un lado, el carácter pacífico de la misma, señalado justamente antes, y en segundo lugar que con la negociación también llega el diálogo. Precisamente, autores clásicos de la diplomacia como Nicholson o Watson (Davis Cross, 2007) definen diplomacia como diálogo y negociación. Lassa Oppenheim también destaca la negociación como una de las tres funciones propias del diplomático (Gómez Mampaso \& Sáenz de Santamaría, 2001)². Esta función, la negociación, está incluso reconocida en la Convención de Viena de $1961^{5}$ cuando la consagra como propia de la diplomacia.

d) En cuarto lugar, diplomacia puede ser entendida como un conjunto de funcionarios que trabajan para que un Estado pueda cumplir con sus objetivos internacionales. Estaríamos hablando, pues, del servicio diplomático como un cuerpo de administración del Estado que trabaja para la puesta en práctica de la política exterior.

f) Por último, en quinto lugar, Sir Peter Marshall habla de "diplomatic" como el adjetivo que marca el comportamiento que debe guiar la conducta de aquellos que tratan de alcanzar los objetivos formulados por los órganos centrales. Se trata de un código de

3 Una definición de diplomacia tradicional "aquella actividad ejecutora de la política exterior de un sujeto de derecho internacional, al servicio de los intereses nacionales o generales de la sociedad internacional, llevada a cabo por órganos $y$ personas debidamente representativos del mismo, ante otro $u$ otros sujetos de derecho internacional, para, por medio de la negociación alcanzar, mantener o fortalecer transaccionalmente la paz" (Vilariño, 2007, p. 79).

4 Además de la negociación habla de la observación y la protección.

5 Artículo 3.e 
actuación internacional que tiene implicaciones en el desempeño de aquellos que realizan la actividad diplomática.

Por ello, no hay ninguna duda de que diplomacia es un concepto polisémico y, precisamente por esto, en algunas ocasiones se usa de forma errónea al aplicarlo como sinónimo de otros conceptos que, si bien pueden ser similares, no son ni mucho menos iguales.

Uno de estos conceptos es precisamente el de política exterior. La relación entre política exterior y diplomacia no es sencilla y habitualmente nos lleva a equívocos. La política exterior puede ser definida como las líneas generales que el gobierno marca para la acción exterior del Estado, mientras que la diplomacia no es más que la ejecución o puesta en práctica de esa política. Esta distinción estaría en consonancia con el segundo significado destacado por Sir Peter Marshall y en línea con esto, algunos autores hablan de una relación complementaria aunque sería mucho más correcto hablar de relación completiva. Por ello, podemos decir que el elemento clave que distingue a la política exterior de la diplomacia es la separación entre la fase de formulación y la de ejecución. La política exterior es formulada por los órganos centrales e implementada esencialmente por los órganos exteriores, aunque en ocasiones los primeros también participan en la implementación. En estos casos hablamos de diplomacia directa, como por ejemplo en las cumbres internacionales ${ }^{6}$ donde los líderes se relacionan los unos con los otros.

Una vez aclaradas las funciones propias de la diplomacia y de la política exterior, la pregunta es qué entendemos por órganos centrales y exteriores. Como hemos avanzado anteriormente, los órganos centrales son aquellos entes de la administración pública que se encargan del diseño de la política exterior. Desde el punto de vista jurídico, los órganos centrales están claramente definidos en el artículo 7.2.a de la Convención de Viena de 1972 sobre el Derecho de Tratados donde se establece de forma explícita que se trata de órganos plenipotenciarios que no necesitan de la acreditación para obligar internacionalmente a sus Estados. Por ello, entendemos que los órganos centrales serán:

a) La Jefatura del Estado, b)la Jefatura del Gobierno, c) el Ministerio de Relaciones Exteriores, d) el Ministerio de Defensa, e) cualquier otro ministerio que esté implicado en la política exterior, f) cualquier otro órgano que sin ser un ministerio pueda estar implicado en el proceso de toma de decisiones de la política exterior, como es el caso del Consejo de Seguridad Nacional en los Estados Unidos.

La Jefatura del Estado -independientemente del tipo de régimen político- asume la más alta representación exterior del Estado. Es por ello que algunos autores como Javier Pérez de Cuellar afirman que el Jefe del Estado encarna el ius representationis omnidoe (Pérez de Cuellar, 1997).

Así, teniendo en cuenta lo dispuesto en la Convención de Viena de 1972, en España la Jefatura de Estado puede ser considerada como un órgano central de la política exterior aunque carece de competencias materiales en la fase de formulación. Si bien es cierto que el Jefe del Estado no participa en la formulación de la política exterior más allá de algunas cuestiones formales como la acreditación de diplomáticos, sí que tiene un rol destacado en la ejecución de la misma. No obstante, este análisis responde a una aproximación tradicional de la diplomacia que estaría en consonancia con un enfoque excesivamente convencional de las relaciones internacionales
La política exterior es formulada por los órganos centrales e implementada esencialmente por los órganos exteriores 
asumiendo que los actores principales de las mismas son los Estados que interactuan entre sí de manera bidireccional.

Gráfico 1. Interacción Estado-Estado en la diplomacia tradicional

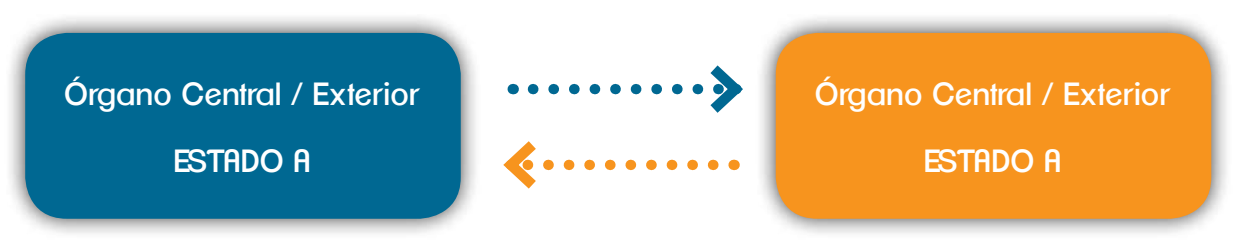

FUENTE: Elaboración Propia

La principal carencia es que esta visión tradicional de la diplomacia no atiende a las nuevas realidades, mayoritariamente actores no-estatales que gozan de una gran presencia y sobre todo influencia en la sociedad internacional actual. De este modo, si nos quedamos en una visión tradicional de la institución diplomática estaríamos obviando la emergencia de nuevos actores tales como los turistas, las empresas multinacionales o las ONGs. Por ello, junto con la denominada diplomacia tradicional debemos atender a los postulados que nos plantea la diplomacia no-tradicional. Es precisamente aquí donde encajan estas nuevas realidades de las que se va a ocupar con la diplomacia pública.

Una vez hemos ampliado el concepto de diplomacia cabe preguntarse qué es la diplomacia pública. El concepto se remonta a 1965 cuando el entonces decano de la Fletcher School of Diplomacy-Edmund Gullion- le dotó de su significado actual ${ }^{7}$. Se trata de una nueva forma de actuar en el ámbito internacional en la que a) gobiernos, grupos privados e individuos b) tratan de influir en las opiniones de pueblos y gobiernos c) con el objetivo de ejercer una influencia en las decisiones de política exterior.

La visión de la diplomacia pública desarrollada por Gullion encaja perfectamente con la de otro de los grandes estudiosos del concepto diplomacia pública, Mannheim (Mannheim, 1994). Jarol Manneheim establece cuatro tipos de contactos diplomáticos que vienen determinados por quién y para quién se lleva a cabo la acción:

a) Gobierno-a-Gobierno (Government to Governement G-t-G): Serían los contactos entre lo que nosotros hemos denominado órganos centrales y que algunos autores han calificado como diplomacia directa.

b) Diplomático-a-Diplomático (Diplomat-to-Diplomat o D-t-D): Serían los contactos entre órganos exteriores desarrollados por las misiones diplomáticas ya sean éstas de carácter permanente o especial.

c) Pueblo-a-Pueblo (People-to-People): Acciones tales como intercambios culturales, educativos, civiles, etc... ya estén propiciados por los Estados a través de fundaciones, asociaciones, etc... o por comunidades transnacionales (diásporas, migratorias etc...)

7 "the means by which governments, private groups and individuals influence the attitudes and opinions of other peoples and governments in such a way as to exercise influence on their foreign policy decisions". 
d) Gobierno-Pueblo (Goverment-to-People) en este último caso estaríamos hablando de diplomacia pública propiamente dicha ya que ésta debe ser entendida como la acción de un gobierno que busca influir en la opinión pública o en personas de gran relevancia con el único objetivo de alcanzar sus metas en política exterior. Esta es la razón por la que algunos autores como Berridge hablan de propaganda o incluso "Red Tape". Otros autores como Paul Sharp, hablan del "dark side" como un ejemplo de mala práctica pero sin cuestionar la propia diplomacia pública (Melissen, 2005).

Mientras que a) y b) son ejemplos claros de diplomacia tradicional c) y d) son dos ejemplos de diplomacia no-tradicional. Si bien es cuestionable que c) sea un caso de diplomacia pública, de lo que no hay ninguna duda que d) lo sea. Volviendo al caso de la Jefatura del Estado y de la Corona Española, podemos afirmar que su acción exterior se enmarca tanto en la diplomacia tradicional (Gobierno-a-Gobierno) y como dentro de la diplomacia no tradicional o diplomacia pública (Gobierno-a-Pueblo).

\section{Gráfico 2. La diplomacia según Mannheim}

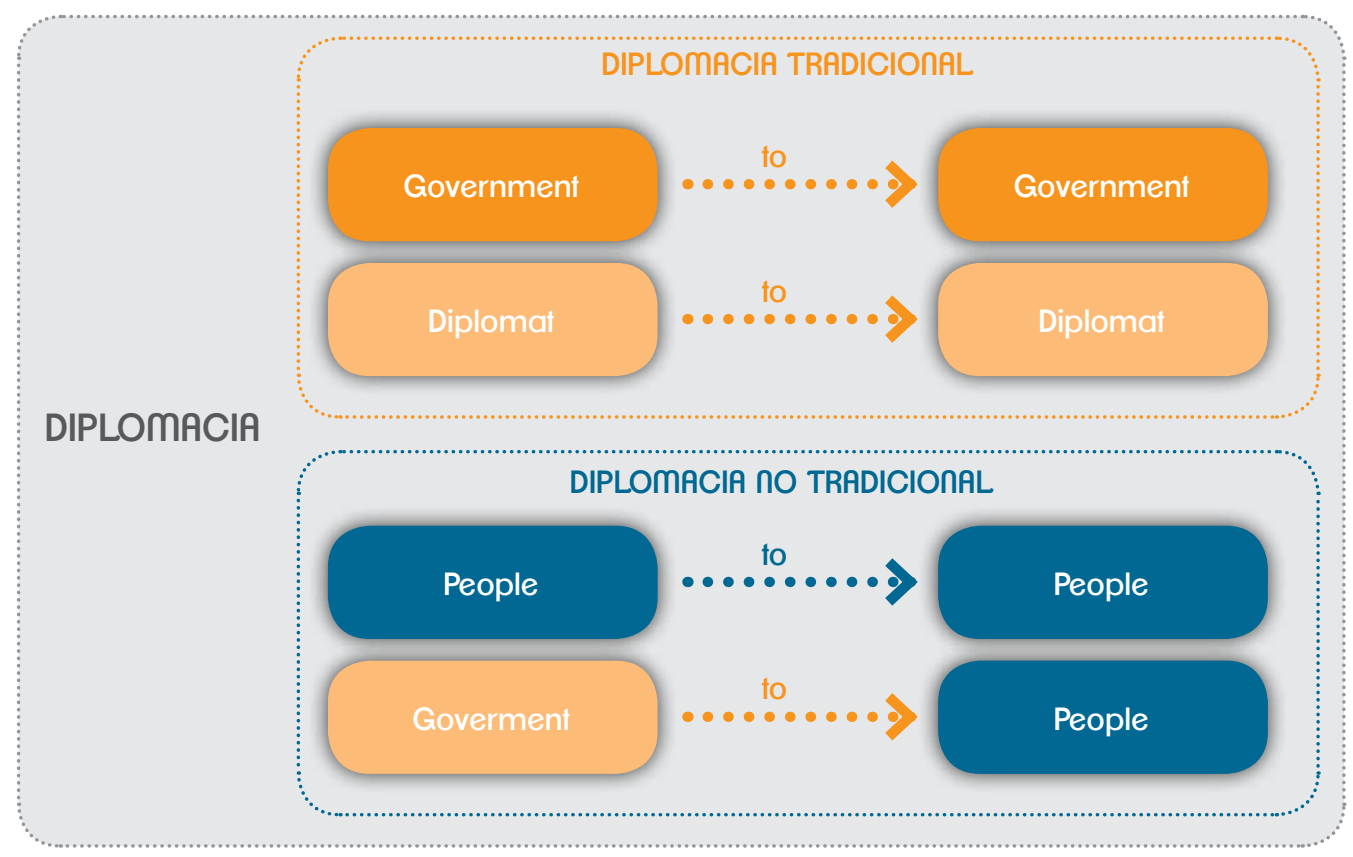

FUENTE: Elaboración Propia

Las visiones de Gullion y Mannheim coinciden con la otro de los autores clásicos en el campo, Hans Tuch ${ }^{8}$. El que fuera miembro del Foreign Service destaca que la diplomacia pública es la acción de un gobierno que comunica (agente activo) a un pueblo (agente pasivo) un mensaje basado en ideas, valores, cultura, instituciones y metas de un Estado. He aquí la novedad, la inclusión de un mensaje con intencionalidad.

8 "a government's process of communicating with foreign publics in an attempt to bring about understanding for its nation's ideas and ideals, its institutions and culture, as well as its national goals and policies" (Tuch, 1990, p. 3) 
Si bien es cierto que los trabajos de Guillion, Mannheim y Tuch aportan una dosis sustantiva de originalidad, no es menos cierto que encontramos grandes diferencias entre la diplomacia tradicional y la diplomacia pública. Siguiendo a estos tres autores vemos que tanto en la diplomacia tradicional como en la pública encontramos:

a) Un emisor que es directa o indirectamente el gobierno/estado (Gullion, Mannheim, Tuch).

b) Un destinatario no es necesariamente un Estado (Gullion, Mannheim, Tuch).

c) Un mensaje con un contenido público (Hans Tuch).

Por ello, para distinguir y entender este nuevo tipo de diplomacia necesitamos otro aspecto más que los aportados por Gullion, Mannheim y Tuch. La diferencia fundamental la aporta Jan Melissen (Melissen, 2005) que señala a la ausencia de reciprocidad en el flujo de información en la relación diplomática como clave para diferenciar entre diplomacia pública y tradicional. En otras palabras, en una relación diplomática tradicional la relación es bidireccional. Los diplomáticos desarrollan las funciones establecidas en el artículo 3 de la Convención de Viena de 1961 en una interacción constante con las autoridades del Estado receptor o con otros diplomáticos. La relación diplomática tradicional, que anteriormente hemos definido como diálogo y negociación es, por tanto, bidireccional mientras que el caso de la diplomacia pública, con independencia de quien sea el emisor o el receptor, es unidireccional. Dicho de otro modo, siguiendo la concepción de Melissen, y al contrario de lo que ocurre en la diplomacia tradicional en la diplomacia pública el agente pasivo no tiene capacidad de influir en el agente activo.

Gráfico 3. Diplomacia pública según Tuch y mellisen

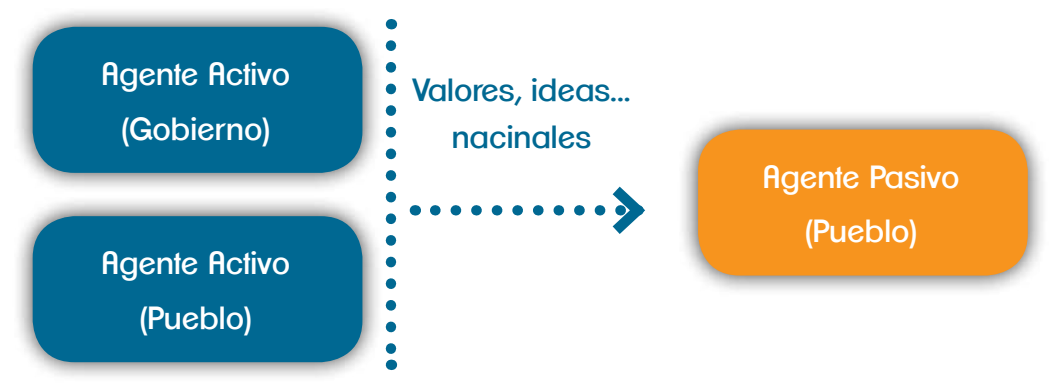

FUENTE: Elaboración Propia

Por lo tanto, cuando hablamos de diplomacia pública es importante que identifiquemos los siguientes tres elementos:

a) Un agente activo - generalmente un Estado- que trata de influir en un agente pasivo que suele ser una sociedad.

b) Un mensaje con importante contenido público.

c) Una interacción unidireccional del agente activo al pasivo sin posibilidad de contestación.

La Corona de España, en su sentido amplio, es un actor especial para la política exterior ya que desde su origen combina las dos facetas de la diplomacia, la tradicional y la no-tradicional. Por un lado, la Corona juega un importante papel dentro de la denominada diplomacia tradicional, 
pues ejecuta la política exterior a través de la diplomacia directa con visitas de estado, asistencia a cumbres internacionales, acreditaciones de embajadores o recepciones al cuerpo diplomático. A pesar de ello, la Corona es también uno de los máximos exponentes y precursores de la diplomacia pública española. Precursora en tanto en cuanto durante los últimos años del Franquismo, el Rey Juan Carlos y la Reina Sofía -en calidad de Príncipes y después de Reyesfueron la mejor imagen de España en el exterior.

Por ello, se puede afirmar que la Corona se ha constituido como un pilar fundamental para la diplomacia española, tanto de la tradicional como de la no- tradicional (pública). El motivo que sustenta esta afirmación son las especiales características de la misma: neutralidad política, continuidad e identificación con el Estado.

\section{La Corona y la diplomacia}

La Constitución Española del 1978 dedica su Título II (art. 56-62) a la Corona Española. Allí se regulan diferentes aspectos de la misma, entre otros su implicación en la política exterior (Alcón Yustas, 2014). En todo caso, estas tareas forman parte de lo que hemos denominado diplomacia tradicional ya que se enmarcan dentro de una visión menos innovadora y más estatista de la institución diplomática.

\subsection{Diplomacia tradicional}

La diplomacia tradicional se desarrolla -de forma directa o indirecta- entre dos Sujetos de Derecho Internacional en un régimen de interacción bidireccional para tratar asuntos de diversa índole. De acuerdo a las categorías de Mannheim estaríamos hablando de contactos:

a) Government-to-Government o G-t-G.

b) Diplomat-to-Diplomat o D-t-D.

c) Incluiríamos una tercera categoría que sería Goverment-to-Diplomat o G-t-D.

Dentro de las tareas de diplomacia tradicional desarrolladas por la Corona pueden hacerse dos grandes apartados usando como criterio el lugar físico donde se celebra el acto. Así podemos distinguir entre 1) actos celebrados en España y 2) actos celebrados fuera de España:

1) Los actos celebrados en España son eventos desarrollados o protagonizados, esencialmente, por el Rey en su condición de Jefe del Estado. Normalmente, estas acciones están recogidas dentro de sus atribuciones constitucionales por lo que su papel está claramente definido y limitado. A su vez, dentro de este tipo de actos podemos distinguir entre:

1.1) Actos dedicados a los diplomáticos españoles. En este punto podemos destacar la acreditación mediante carta credencial de los diplomáticos que van a representar al Reino de España en el exterior. Este acto tiene un claro carácter doméstico aunque juega un papel esencial para que nuestros diplomáticos puedan llevar a cabo encuentros del tipo D-t-D y G-t-D.

1.2) Actos dedicados a los diplomáticos extranjeros acreditados en España (López Caballero, 2006) $)^{9}$. En este segundo tipo de actos destacamos dos. El primero, la Ceremonia de

La Corona se ha constituido como un pilar fundamental para la diplomacia española, tanto de la tradicional como de la notradicional (pública) 
Presentación de las Cartas Credenciales y el segundo, la tradicional, y al tiempo informal, recepción que el Rey ofrece al Cuerpo Diplomático acreditado en España. En el primer caso, el Rey, en su condición de Jefe del Estado, recibe las credenciales, firmadas por sus homólogos, que acreditan a los diplomáticos extranjeros como representantes en España. En el segundo acto, el Rey se relaciona con los diplomáticos acreditados ante él con el fin de cumplir con el artítulo 3.e de la Convención de Viena de 1961: fomentar de las relaciones entre los Estados ${ }^{10}$. En ambos casos -de acuerdo a Mannheim- estaríamos hablando de una relación G-t-D.

1.3.) Actos vinculados a visitas oficiales o de Estado ${ }^{11}$. Cuando un dignatario extranjero visita España, el Rey, en su condición de Jefe de Estado, celebra diferentes recepciones en su honor. Normalmente, se suele organizar una cena durante la primera noche del viaje oficial de los mandatarios. En todo caso, parece claro que estaríamos hablando de una relación G-t-G, es decir, diplomacia directa. En el caso del Rey Juan Carlos I, su última recepción como anfitrión fue al Presidente de México, Peña Nieto.

2) Los actos celebrados fuera de España.

Una de las funciones que la Constitución atribuye expresamente al Rey es la representación del Estado en el exterior. El artículo 56.1 establece que el Rey “asume la más alta representación del Estado español en las relaciones internacionales, especialmente con las naciones de su comunidad histórica” (Constitución Española, 1978). La función de representación está recogida en el artículo 3 de la Convención de Viena de 1961, por lo que puede considerarse como parte de la diplomacia tradicional.

En los viajes ${ }^{12}$ llevados a cabo, no sólo por el Rey sino por toda la Familia Real, se representa a España mediante lo que hemos denominado diplomacia directa (G-t-G). El objetivo es defender los intereses de España al tiempo que representar al Estado ante otros Estados, Organizaciones Internacionales u otros sujetos de Derechos Internacional Público. Siguiendo a Carlos Fuente (Fuente, 2006) y a Blanca López Caballero (López Caballero, 2006) podemos distinguir entre los siguientes tipos de visitas:

a) De Estado. Aquellas que de acuerdo con el Gobierno español se realizan tras una invitación oficial procedente del Jefe del Estado del país que se va a visitar. Su duración suele rondar los tres o cuatro días y en el caso de España se reserva en exclusiva a los Reyes. Previamente una delegación española de la Casa de S.M y del Gobierno -la avanzada - se desplaza al país para fijar los detalles de la visita. Normalmente, en las visitas de Estado los Reyes suelen ir acompañados de un miembro del Gobierno y por el embajador de España allí acreditado. También puede acompañar el embajador del país visitado acreditado en España, así como delegaciones empresariales interesadas en el comercio y en la inversión.

b) De cortesía. Se trata de visitas que se pueden llevar a cabo por invitación o por iniciativa propia para asistir a un acto determinado. Normalmente son funerales de Estado,

10 "fomentar las relaciones amistosas y desarrollar las relaciones económicas, culturales y científicas entre el Estado acreditante y el Estado receptor" art 3.e. de la Convención de Viena de 1961 sobre relaciones diplomáticas

11 La denominación Viaje de Estado está reservada aquellos desplazamientos llevados a cabo por Jefes de Estado, con independencia del tipo de régimen político. En España sólo reciben esta calificación los que realiza el Rey.

12 El anexo 1 recoge todos los viajes llevados a cabo por los Reyes y los Príncipes de Asturias en los últimos 10 años

\section{Una de las}

funciones que la Constitución

atribuye expresamente

al Rey es la representación del Estado en el exterior 
tomas de posesión o actos relacionados con otras casas reales, etc... La organización de los mismos corresponde a la Casa de S.M el Rey apoyada por el Gobierno y en coordinación, siempre, con las embajadas. Estas visitas las realiza tanto el Rey, la Reina como el Príncipe de Asturias, en el caso de Don Felipe.

c) Privadas. Se realizan en el ámbito privado y por ello su organización corresponde en exclusiva a la Casa de S.M. el Rey.

d) De interés. Se tratan de visitas programadas por la Casa de S.M. el Rey por el interés que suscita un asunto concreto. Por ejemplo, el conocimiento de una institución, un evento tal como unas olimpiadas o un foro. Si media una invitación previa se añade el calificativo Visita Oficial.

e) De trabajo. Realizadas para trabajar sobre un asunto concreto.

f) Oficiales. Las realizadas por el Príncipe de Asturias ya que las de Estado se reservan a los Reyes o al Rey en solitario. Las realizadas por la Reina y por el Principe son visitas oficiales al igual que el Presidente del Gobierno, los presidentes de las Comunidades Autónomas, los ministros de Asuntos Exteriores y otros ministros.

De todas estas visitas, sólo la primera y la última (visita de Estado y visita oficial) pueden ser consideras como parte de la diplomacia tradicional. El resto en buena medida formarían parte de su agenda privada o podrían ser consideradas como ejemplos de diplomacia no-tradicional. En cada viaje, el mandatario es acompañado por un séquito oficial o real, técnico y de servicio. En el caso de los miembros de la UE, el número de personas que componen el séquito oficial está limitado dependiendo del tipo de visita ${ }^{13}$. Del mismo modo, aunque pueden existir variaciones, una visita de Estado -especialmente en Occidente- está más o mejor establecida en tres o cuatro días que se distribuyen con el siguiente esquema:

a) Día 1: Recepción al Jefe de Estado con rendición de honores, generalmente en el aeropuerto. Durante el primer día se celebra un almuerzo privado en la residencia del Jefe del Estado. Por la noche habrá una cena de gala que el Jefe del Estado ofrece a sus invitados y a la que acuden las principales autoridades del país receptor.

b) Día 2: Ofrenda floral a los que dieron la vida por su país por parte del visitante. Se visita el ayuntamiento o las Cámaras legislativas. Después, el Jefe del Estado se entrevista con el Gobierno. La cena corre a cuenta del visitante que, generalmente, se vale de su Embajada para su celebración.

c) Día 3: Se celebra algún tipo de visita de carácter cultural, generalmente en la capital, aunque se puede desplazar a una ciudad vecina. El anfitrión abandonará el país en una ceremonia similar a la que se celebró en el aeropuerto durante la llegada ${ }^{14}$.

Dentro de esta categoría merecen ser destacados dos tipos de actos en los que la Corona es protagonista de excepción. En concreto, me estoy refiriendo a las Cumbres Iberoamericanas y a las tomas de posesión de los mandatarios iberoamericanos. Las Cumbres Iberoamericanas son, sin lugar a dudas, el mejor legado internacional que nos deja el Rey Juan Carlos I. Desde

13 En una visita de Estado se limita a 12, de trabajo a 10, de Jefe de Gobierno a 8 Presidente de Comunidad Autónoma a 6, Ministro de Asuntos Exteriores 4 y el resto de ministros tan sólo 3

14 Como anécdota podemos señalar que el primer viaje de Estado del Rey Juan Carlos I fue a Estados Unidos y el último a Omán. En el caso del Rey Felipe VI su primer viaje ha sido al Vaticano.

\section{Las Cumbres} Iberoamericanas son, sin lugar a dudas, el mejor legado internacional que nos deja el Rey Juan Carlos I 
su creación en 1991 el Rey Juan Carlos I ha asistido a todas y cada una de las cumbres, con la única excepción de Panamá 2013 a la que no asistió por evidentes motivos de salud. La nopolitización de la Corona ha permitido que el Rey Juan Carlos I, o el rey, como se le conoce en América Latina, haya logrado importantes avances diplomáticos para España que no estaban al alcance de los Presidentes. Sin ir más lejos, durante la visita a Cuba de 1999 que se desarrolló en el marco de la Cumbre de la Habana su mediación fue clave en la mejora de las complicadas relaciones entre el Presidente Aznar y Fidel Castro.

El segundo de los actos que queríamos destacar es la toma de posesión de los mandatarios Iberoamericanos. La Constitución Española de 1978 atribuye al Rey la más alta representación del Estado, "especialmente con las naciones de su comunidad histórica" (Constitución Española, 1978) entendiendo por éstas, esencialmente, a las de América Latina. Precisamente, gracias a esa característica de continuidad propia de la Corona, Felipe VI, en su condición de Príncipe de Asturias, asumió en 1996 esta función de representación en los actos de toma de posesión en América Latina. En total, Felipe de Borbón ha asistido a 69 tomas de posesión, demostrando así su compromiso no sólo con la democracia sino también con América Latina. Aunque es cierto que se trata de dos ejemplos de diplomacia tradicional -relaciones estatales (G-t-G) - las Cumbres Iberoamericanas han permitido a España hacer uso de la diplomacia pública para promover los valores que España considera suyos o con los que quiere que le identifiquen. En este proceso, la Corona, y sobre todo el Rey Juan Carlos I, han sido determinantes.

Junto al elemento de identificación entre Corona y Estado, también debemos mencionar la neutralidad política y la continuidad para entender el valor añadido que aporta la Monarquía a la diplomacia española. Sin estos tres elementos, España no hubiera podido mantener vivo el vínculo político, económico y cultural que hoy existe entre ella y la comunidad iberoamericana de naciones ${ }^{15}$. Este compromiso con el continente americano se ha visto revitalizado en el Discurso de Proclamación de Felipe VI donde afirmó que "con los países iberoamericanos nos unen la historia y lazos muy intensos de afecto y hermandad ${ }^{16}$ "

\subsection{Diplomacia no-tradicional (diplomacia pública) ${ }^{17}$}

La diplomacia no-tradicional es una evolución de la diplomacia clásica teniendo en cuenta los cambios que se han producido en la sociedad internacional. Dentro de la diplomacia notradicional destaca sobremanera la diplomacia pública que, siguiendo a Tuch, se caracteriza por ser acciones de un gobierno hacia una sociedad con un mensaje donde se transmite los valores de emisor de forma unidireccional. Si nos fijamos en los esquemas de Mannheim hablaríamos de acciones Government-to-People e incluso People-to-People, aunque en la mayor parte de las ocasiones nos damos cuenta que el agente activo no es verdaderamente People sino Government tratando de parecer People para incrementar su credibilidad. Este es precisamente el problema de la diplomacia pública, la ausencia de credibilidad, que ha llevado a algunos autores como

15 "el Rey ha participado activamente, casi siempre en sintonía con el MAE, en la política española hacia las naciones de la pomposamente llamada comunidad histórica" (Molina \& Rodrigo, p. 179)

16 Discurso disponible en http://www.abc.es/casa-del-Rey/proclamacion/20140619/abci-discurso-integro-felipe-tras-201406191151.html

17 Sobre la Diplomacia No-Tradicional en España ver Priego, Alberto, "Spanish Soft power and its structural (nontraditional) model of diplomacy” en Pachecho, Ramón and García, David. (2014). Contemporary Spanish Foreign Policy. London: Routledge.
La diplomacia notradicional es una evolución de la diplomacia clásica teniendo en cuenta los cambios que se han producido en la sociedad internacional 
Berridge a calificarla de mera propaganda. Por eso, en ocasiones se usa a los deportistas, a los actores, a los personajes históricos relevantes para dotar de credibilidad a la diplomacia pública. Aquellos Estados que mantienen la forma monárquica recurren con frecuencia a miembros de sus casas reales para estos menesteres recordando mucho al Diginified Aspect que Bagehot señalaba como función propia de las monarquías (Turner, 2012). Quizás el más claro ejemplo haya sido Lady Di, quien poseía una imagen mucho más amable que políticos británicos como Margaret Thatcher o John Major (Keagan \& Kellner, 2009) ${ }^{18}$.

En el caso de España, esta nueva faceta de la diplomacia está permitiendo una mejora sustancial de la imagen de nuestro país en el exterior. El objetivo principal de la diplomacia pública es la atracción de inversiones y turistas, así como la facilitación de las actividades comerciales de nuestras empresas en el exterior.

Siguiendo a Luis Melgar (Ministerio de Asuntos Exteriores y Cooperación [MAEC], 2012) podemos destacar dos grandes modelos de diplomacia pública, el británico y el francés. La diplomacia pública española se inspira en los dos modelos. Por un lado, recoge del británico la participación de diferentes niveles de gobiernos y agencias relacionadas y por otro lado, del francés incorpora a los elementos culturales en la proyección exterior del Estado. Para demostrar esta afirmación vamos a describir brevemente cuáles son los instrumentos implicados en este proceso y qué valores se quieren proyectar.

Nuestro sistema de diplomacia pública se asienta sobre un tupido entramado institucional. Podemos destacar los siguientes órganos como principales actores implicados en la puesta en funcionamiento de la diplomacia pública española:

a) Las Casas que son un consorcio de instituciones dispersas por la geografía nacional que dividen su actividad por áreas geográficas. Así, podemos destacar Casa América, Asia, Árabe, Sefarad, África y Mediterráneo ${ }^{19}$.

b) La Fundación Carolina que es una institución sin ánimo de lucro que busca acercar la cooperación académica entre España y América Latina.

c) Las Fundaciones-Consejo son entidades público-privadas que tratan de favorecer las relaciones bilaterales de España con otros Estados (EEUU, China, Rusia, Australia, Japón, México, India y Brasil)

d) El Instituto Cervantes, creado a la imagen y semejanza del British Council y de Institut Français, busca desde 1991 la promoción de la lengua española en el mundo.

e) La Agencia Española de Cooperación Internacional y Desarrollo es un órgano dependiente del Ministerio de Asuntos Exteriores y Cooperación que trata de promover la cooperación al desarrollo española en el mundo.

f) Aunque no forma parte propiamente de la estructura de la diplomacia pública hay que destacar el Alto Comisionado para la Marca España que en la actualidad está representado por Carlos Espinosa de los Monteros. Este programa si bien es cierto que

18 "Princess Diana, however briefly, became the most publicized celebrity diplomat of a certain era before her tragic death" (Keagan \& Kellner, 2009 p. 4).

19 Todas "las Casas", con la excepción de Casa Asia y Casa Mediterránea, han sido inauguradas por los Reyes de España. Casa América el 25-7- 1992, Casa África 2007, Casa Árabe 2008 (Nueva Sede), Casa Sefarad 2011 (Nueva Sede) 
formaría parte de la diplomacia pública es una iniciativa que puede ser clasificada como National (re)branding.

g) Aunque no dependen del Ministerio de Asuntos Exteriores y Cooperación se deben mencionar otras agencias como Acción Cultural Española (Ministerio de Cultura/ MAEC), el Instituto de Comercio Exterior (ICEX) o El Real Instituto Elcano (MAEC, 2012) por su especial contribución a la imagen de España en el exterior.

En todo este entramado la Corona juega un papel fundamental en la diplomacia pública española y por ello, sus miembros trabajan de forma coordinada con estos organismos con el único objetivo de poner en práctica las disposiciones formuladas desde el Gobierno. Por esta razón, no es raro encontrar a miembros de la Casa Real asistiendo a reuniones del Instituto Cervantes $^{20}$ o encabezando viajes de cooperación de la AECID ${ }^{21}$. De este modo, y siguiendo lo anteriormente dispuesto, podemos afirmar que la Corona es un actor básico de la política exterior para la ejecución de la política exterior.

Una vez hemos descrito el marco institucional dedicado, casi en exclusiva, a la mejora de la imagen de España ahora queda por dilucidar cuáles son esos valores que se quieren promover en el exterior o con los que se quiere que identifiquen a España. Podemos destacar tres grandes grupos que centran las acciones de la diplomacia pública española:

a) España como defensora de la democracia y de los derechos humanos.

b) España como Estado moderno y desarrollado económicamente.

c) España como una sociedad tolerante, culta y solidaria.

Vamos a analizar brevemente estos tres campos de acción de la diplomacia pública española y valorar cuál ha sido el papel de los miembros de la Casa Real en su promoción.

\section{a) España como defensora de la democracia ${ }^{22}$ y de los derechos humanos ${ }^{23}$.}

Debido al pasado autoritario de España, la diplomacia pública española ha centrado buena parte de sus esfuerzos en cambiar esa imagen de país autoritario por otra más democrática. La promoción de la democracia y de los derechos humanos aparecen calificados como objetivos estratégicos en el informe realizado por el Real Instituto Elcano que tiene como meta marcar las líneas generales de la política exterior española (Molina, 2014). En todo este proceso, gracias a las caracterísiticas de no-politización, continuismo y credibilidad, la Corona ha jugado un papel muy relevante. Tal es así, que incluso antes de la promulgación de la Constitución, el Rey Juan Carlos I ya guardaba en su portafolios un buen número de discursos donde afirmaba y reafirmaba el compromiso de la Monarquía con la democracia y los derechos humanos.

20 "Don Felipe y doña Letizia presidieron una sesión de trabajo poco antes de concluir la Reunión Anual de Directores en Alcalá de Henares" Nota de prensa Instituto Cervantes, 21 de julio de 2011. Disponible en http://www.cervantes.es/sobre_instituto_cervantes/prensa/2011/noticias/nota_dia_20_reunion_directores.htm

21 "Viaje de Cooperación de SM la Reina a Guatemala" Nota de Prensa AECID, 13 de marzo de 2014. Disponible en http://www.aecid.es/ES/Paginas/Sala\%20de\%20Prensa/Noticias/2014/2014_03/2014-03-13-reina-guatemala.aspx

22 La democracia está recogida dentro los objetivos estratégicos de la política exterior, concretamente en el 2.b "Reforzar la calidad de la democracia española a través de la acción exterior" y en el 2.c "proyectar una identidad internacional de democracia avanzada y apoyar (sin injerencias) la expansión de sistemas políticos democráticos" (Molina, 2014, p. 50).

La Corona juega un papel fundamental en la diplomacia pública española y sus miembros trabajan de forma coordinada con el único objetivo de poner en práctica las disposiciones formuladas desde el Gobiemo 
Por encima de otros actos merece ser destacado el primer viaje de Estado del Rey Juan Carlos I a los Estados Unidos. Para constextualizar debe señalarse que era la primera vez que un monarca español visitaba el continente americano. El 2 de junio de 1976, El Rey Juan Carlos I anunció ante el Congreso de los Estados Unidos el compromiso de la Corona con la democracia y con los derechos humanos. Además de este decisivo discurso en su viaje a Estados Unidos, Juan Carlos I concedió una entrevista al semanario norteamericano Newsweek donde calificó al entonces Primer Ministro Arias Navarro como un unmitigated disaster (Gallego-Díaz, 1976) provocando inmediatamente su dimisión. En este preciso punto podemos poner el punto de inicio de la transformación internacional de España. Nuestro país dejaba de ser percibido como un régimen autoritario para convertirse años después en un promotor de la democracia y de los derechos humanos en el mundo.

Muchos son los casos en los que podemos destacar el compromiso de la Corona con la democracia y los derechos humanos. Por ejemplo, en la visita a la Argentina de Videla (1978) el Rey Juan Carlos, percibido ya como un monarca reformista, pronunció un discurso que molestó enormemente a la Junta Militar. Sus palabras, marcadas por el proceso de transición que se vivía en España, fueron una defensa sin fisuras de la democracia y de los derechos humanos ${ }^{24}$. Este compromiso quedó de nuevo renovado en octubre de 1979 en un discurso pronunciado en el Consejo de Europa, organización que vela por el respeto de los derechos humanos en Europa. En este mismo viaje el Rey Juan Carlos I recibió el doctorado "Honoris Causa" por la Universidad de Estrasburgo por su defensa de los derechos humanos durante el periodo de la transición ${ }^{25}$.

Sin lugar a dudas el momento más complicado para Juan Carlos I y para España fue el intento de Golpe de Estado de 1981. Gracias a la decisiva intervención del Rey el golpe fue desmantelado, lo que siguiendo las tesis de Antonio Camuñas ${ }^{26}$ reforzó la imagen democrática del Rey y sobre todo de la propia España ${ }^{27}$.

El primer reconocimiento internacional a ese cambio de imagen fue la concesión al Rey Juan Carlos I del Premio Carlomagno (1982). La concesión de este galardón, que cuenta con importantes personalidades como Jean Monnet, Robert Schumann o Konrad Adenauer, suponía la admisión de España en el "Club de las Democracias Europeas". De este modo, se comenzaba a identificar a nuestro país no sólo como una democracia occidental, algo que era un logro en sí mismo, sino como un promotor de los valores democráticos y de los derechos humanos en el exterior. Junto a este importante logro, a título individual se reconocía la figura del Rey Juan Carlos por su labor como punta de lanza de la transformación de España. Este premio era la prueba definitiva de que España había dejado de ser un régimen autoritario.

24 "El orden político y la paz social no pueden tener otros fundamentos que la dignidad de la persona, los derechos humanos inviolables que le son inherentes y el respeto por la ley" (Ayllon, 2014).

25 "el Rey de España, don Juan Carlos, será investido doctor honoris causa por la Universidad de Estrasburgo (Francia), que le concedió el título el año pasado, en homenaje a la defensa de los derechos humanos por él realizada durante el período de transición democrática" (El País, 1979).

26 "La eficacísima labor llevada a cabo personalmente por S.M. el Rey tanto al personificar a esa nueva España en los cinco continentes, como su contundente respuesta al intento de golpe de Estado" (MAEC, 2012, p. 110)

27 "It has so far been Spain's most successful experiment with democracy ever. In 1982, it joined NATO; in 1986, a mere five years after 23-F (as the 1981 coup d'état is commonly referred to), Spain became a full-fledged member of the European Union" (Veuger, 2014).

\section{El primer}

reconocimiento internacional a ese cambio de imagen fue la concesión al Rey Juan Carlos I del Premio Carlomagno (1982) 
La identificación entre la Corona y España fue clave para este cambio y el certificado definitivo fue la adhesión de España a las Comunidades Europeas (1986). La integración de España en la UE supuso el inicio de la fase final de modernización de España ${ }^{28}$. Tras 40 años de aislamiento internacional, España tuvo que adaptarse a los estándares europeos que llegaron unidos al proceso de integración europeo. De nuevo la Corona jugó un papel muy relevante y por ello fue reconocido internacionalmente. El propio presidente de la Comisión Durao Barroso no dudó en calificar al Rey Juan Carlos I como "artífice y defensor de la democracia y valedor fundamental del europeísmo” (Pérez \& Abellán, 2014). Esta fe en Europa como solución a los problemas de España se ha trasmitido de padre a hijo mostrando de nuevo el valor de la continuidad institucional que aporta la monarquía. Como prueba valgan las palabras del Rey Felipe VI en su Discurso de Proclamación al afirmar que "hoy España es Europa ${ }^{29 "}$.

Si hasta ahora hemos hablado de un tipo de diplomacia pública G-t-G, no debemos olvidar la que Mannheim califica People to People (P-t-P). Uno de los aspectos más exitosos de la diplomacia pública P-t-P son los diferentes premios que se conceden bajo el patronazgo de la Corona. Siguiendo con esta línea de fomento de la democracia y de los derechos humanos cabe destacar los Premios de Derechos Humanos Rey de España ${ }^{30}$ que desde 2005 conceden el Defensor del Pueblo y la Universidad de Alcalá de Henares.

En este sentido, mención especial merecen los Premios Príncipe de Asturias de la Concordia que premian a personas e instituciones que han demostrado un compromiso decidido con la defensa de los derechos humanos y de la democracia. Sobre los Premios Príncipe de Asturias es necesario decir que se trata de un ejemplo de diplomacia pública del tipo People-to-People ya que es una fundación (Fundación Príncipe de Asturias) y no el Estado quien los gestiona. Las nominaciones son abiertas y el jurado está compuesto por personalidades de destacado prestigio en ese campo. En resumen, podemos incluir estos actos dentro de un concepto amplio de diplomacia pública (P-t-P) que tiene el claro objetivo de reforzar el compromiso entre la Corona, democracia y derechos humanos para que España aparezca como un promotor internacional de estos valores.

En la línea iniciada por el Rey Juan Carlos, el Rey Felipe VI ${ }^{31}$ también se ha mostrado como un ferviente defensor de la democracia y de los derechos humanos. En el que fue su último discurso como heredero de la Corona, y precisamente en el marco de los Premios Príncipe de Asturias, Felipe VI renovó los votos de España con la democracia y con Europa al afirmar que "La sociedad española está firmemente instalada en la democracia y la libertad" y que precisamente por ello "somos una sociedad fiel a nuestra vocación europea ${ }^{32}$ ". Se trataba pues, de una declaración de principios personales e institucionales que sigue perfectamente el legado de su padre.

28 En este proceso resultó de gran ayuda el apoyo de la Reina Beatriz de Holanda. (d'Oliveira, 2012).

29 Discurso disponible en http://www.abc.es/casa-del-Rey/proclamacion/20140619/abci-discurso-integro-felipe-tras-201406191151.html

30 Sobre los Premios Derechos Humanos Rey de España http://premioddhh.defensordelpueblo.es/

31 El Rey Felipe VI, siendo Príncipe de Asturias, cursó estudios sobre Instituciones Comunitarias en Bruselas.

32 Ver Palabras de S.A.R. el Príncipe de Asturias en la ceremonia de entrega de los Premios Príncipe de Asturias de 2013. Disponible en http://www.fpa.es/es/sar-el-principe-de-asturias/discursos/2013.html

\section{En la línea iniciada por el Rey Juan Carlos, el Rey Felipe VI también se ha mostrado como un ferviente defensor de la democracia y de los derechos humanos}


Estos son tan sólo algunos ejemplos que muestran el compromiso de la Corona con la democracia ${ }^{33}$ y los derechos humanos. Se trata de un compromiso que gracias a las características de no-politización e identificación con el Estado de la Corona han servido para transformar la imagen política de España en el exterior. Es, por tanto, un ejemplo y un éxito de la diplomacia pública española en el que la Corona ha jugado un papel muy importante.

\section{b) España como Estado moderno y desarrollado económicamente ${ }^{34}$.}

Otro de los elementos que la diplomacia pública española se ha empeñado en mostrar es la modernización y el desarrollo de España. Desde los años 80, nuestro país ha emprendido un proceso de modernización económica y social que nos ha situado en línea con los Estados más avanzados del mundo. La evolución de la economía española ha sido muy importante pasando de tener una renta per cápita de 6031 en 1980 a los $28.273 \$$ actuales $^{35}$. Entre algunas de las causas del milagro económico español cabe destacar la internacionalización de la economía, un proceso que se ha visto intensificado exponencialmente en los últimos años como forma de compensar la recesión económica. Por esta razón, en los últimos años se ha apostado por un modelo económico basado en las exportaciones y el turismo -sobre todo extranjero- tal y como demuestran los siguientes gráficos:

Gráfico 4. Porcentaje del PIB dedicado a la exportación de bienes y servicios

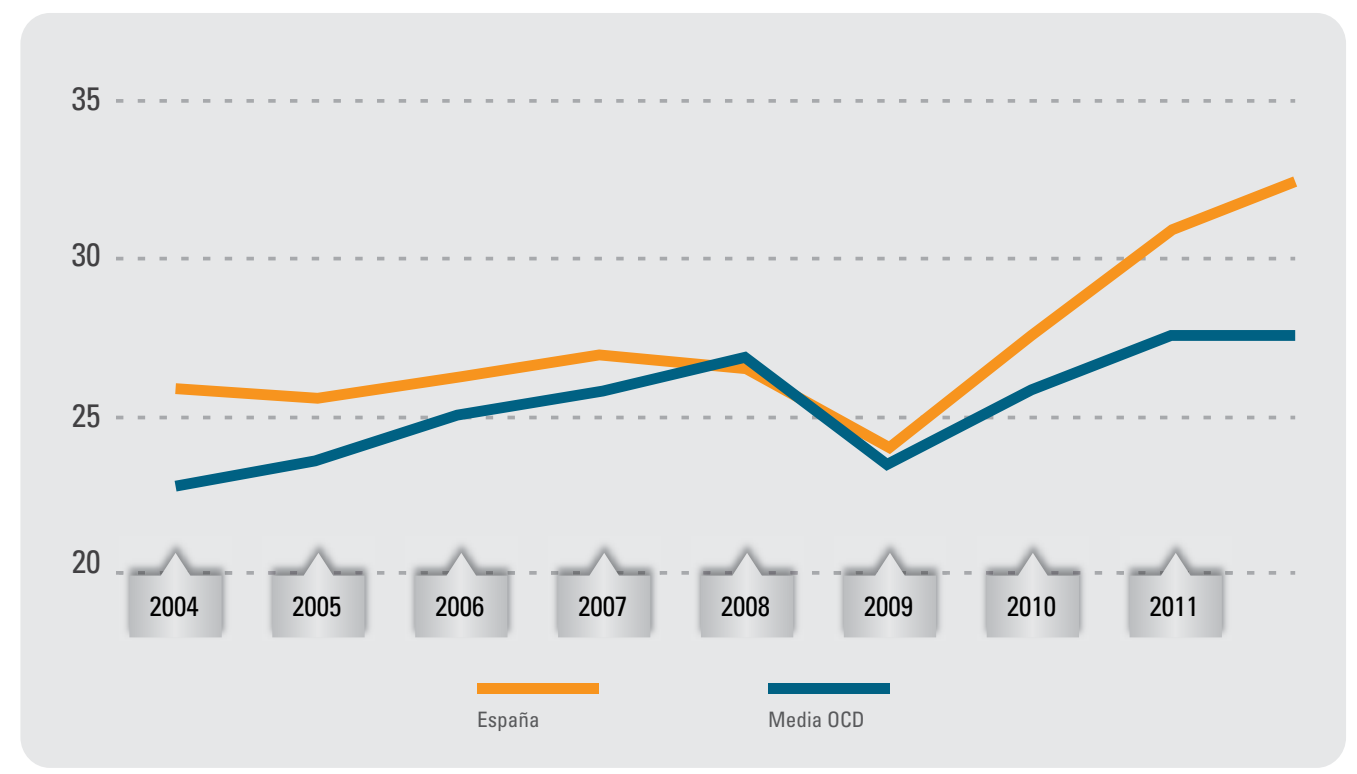

FUENTE: Banco Mundial

33 "Spain's King Juan Carlos oversaw the country's transition to democracy in the 1970s, but he had never ruled as an absolute monarch in the first place" (Hamid, 2011).

34 Este punto aparece recogido en el informe del Real Instituto Elcano dentro del objetivo estratégico 4 de política exterior. (Molina, 2014).

35 Datos recogidos del Banco Mundial 
Gráfico 5. Porcentaje del PIB dedicado al turismo

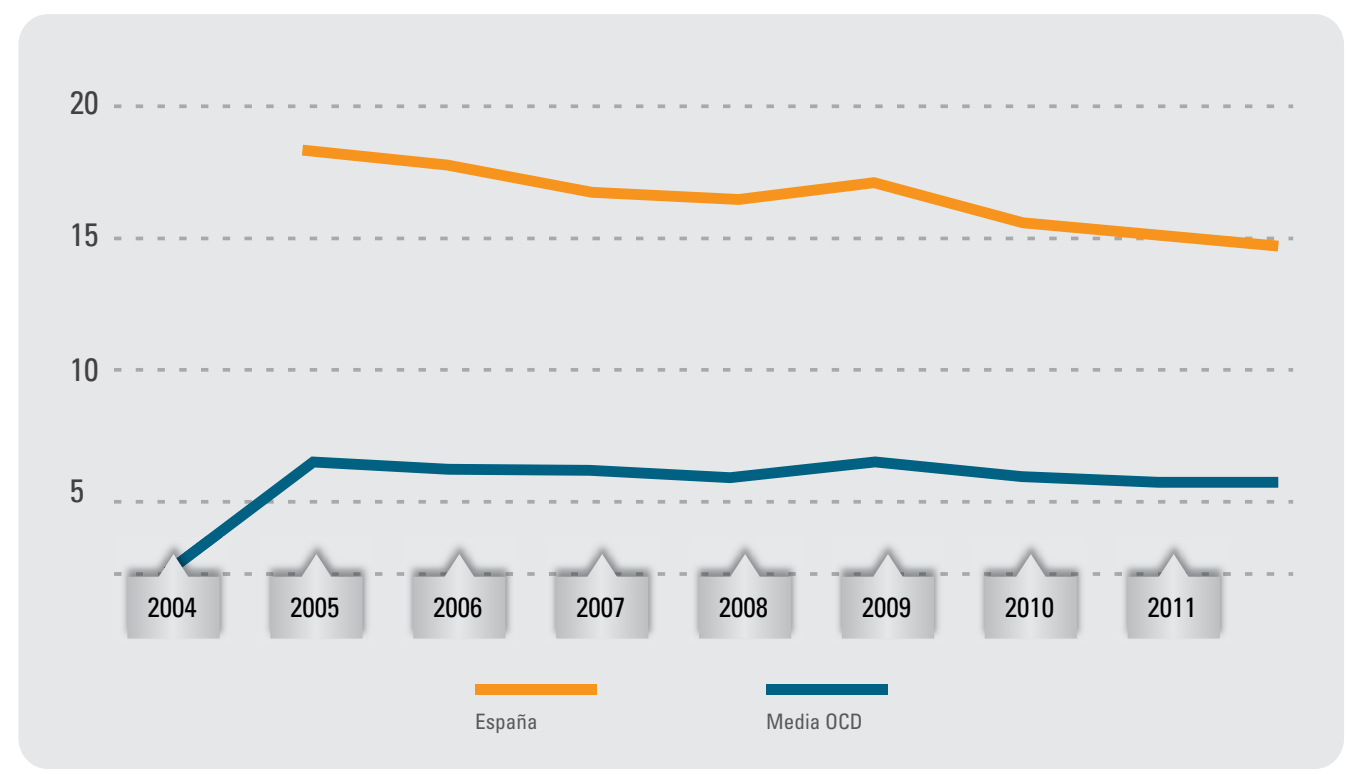

FUENTE: Banco Mundial

El proceso de internacionalización y modernización económica, que sin lugar a dudas tiene un innegable beneficio interno, necesita ser publicitado de cara al exterior para mantenerse vivo y retroalimentarse. Por esta razón, a través de la diplomacia pública, se está llevando a cabo un proceso de publicitación de los éxitos económicos con el objetivo de atraer turistas, inversiones y a facilitar la internacionalización de las empresas españolas. Al igual que ocurre con los aspectos políticos de la diplomacia pública, la Corona también se ha configurado como actor básico para la difusión del modelo o milagro económico español.

Esta es la razón por la cual, desde los años 80, España ha buscado la organización de eventos internacionales como escaparate para enseñar al mundo el proceso de modernización de nuestra economía y de nuestra sociedad. Podemos destacar los siguientes eventos como los más importantes para mostrar el atractivo de nuestro país de cara a atraer inversiones y promover el turismo en España:

a) Mundial de Futbol 1982.

b) Juegos Olímpicos de Barcelona 1992.

c) Exposición Universal de Sevilla 1992.

d) Madrid Capital Europea de la Cultura 1992.

e) Santiago de Compostela Capital Europea de la Cultura 2000.

e) Salamanca Capital Europea de la Cultura 2002.

e) Foro Universal de las Culturas Barcelona 2004.

f) Exposición Universal de Zaragoza 2008.

g) San Sebastián Capital Europea de la Cultura 2016

Aparte de estos éxitos internacionales, España también optó a la organización de otros eventos que lamentablemente no fueron concedidos a nuestros país. Destaca sobre los demás los dos 
intentos de Madrid por organizar los Juegos Olímpicos, en cuya defensa el entonces Príncipe Felipe jugó un rol muy destacado. El objetivo de todos y cada uno de estos acontecimientos internacionales era lograr que España fuera percibida en el exterior como un ejemplo de modernización capaz de atraer turismo e inversión. La diplomacia pública española buscaba transmitir la eficacia española para abrir las puertas a nuestras empresas de nuevos mercados. Aunque es cierto que ninguno de estos eventos se celebraron en el exterior, todos y cada uno de ellos son considerados actos de diplomacia pública, ya que el agente pasivo al que estaba destinado el mensaje eran sociedades extranjeras. Incluso, estos actos han gozado de mayor influencia internacional que los celebrados en el exterior, ya que el público potencial era toda la humanidad.

La otra gran línea de acción de la diplomacia (económica) pública son los viajes de los miembros de la Casa Real. A través de estos viajes oficiales, privados o de cortesía, se buscaba influir sobre los centros de poder favoreciendo encuentros con líderes, visitando centros de investigación de alto prestigio, o asistiendo a foros internacionales relevantes. Como ejemplo de este tipo de viajes de diplomacia (económica) pública nos puede servir el realizado por los entonces Príncipes de Asturias a California y Florida (noviembre 2013). En los siete días que duró la visita, los Príncipes de Asturias realizaron un sinfín de actividades entre las que cabe destacar la inauguración una exposición organizada por Acción Cultural Española en Miami, la presidencia del foro de negocios "Spain Innovation \& Technology" en Silicon Valley, un encuentro con el fundador de Facebook o la inauguración de la XXX edición de la Feria del Libro de Los Ángeles. En todo caso, el viaje de los Príncipes debe servir de ejemplo para mostrar como la diplomacia pública busca mostrar al exterior la modernización económica y social de España. Para ello, las características de no-politización, continuidad e identificación con el Estado se antojan fundamentales.

Fruto de los esfuerzos de diplomacia pública llevados a cabo por los diferentes gobiernos, España ha alcanzado importantes avances en la internacionalización económica. En los años 2011 y 2012, el sector exterior aportó un 2,2 y un 2.5 del PIB respectivamente en un momento importante en el que la demanda interna era débil y que la economía se contraía. Por lo tanto, la economía ha buscado compensar en el exterior los problemas económicos domésticos. Así, las empresas españolas han logrado concesiones de grandes proyectos internacionales -como el AVE del Desierto o el Canal de Panamá- que no hubieran sido posible sin esta política de diplomacia pública.

En esta misma línea, empresas españolas como Zara, BBVA o Abengoa se han convertido en marcas de prestigio y en buena medida se debe a una política acertada de diplomacia pública. Una de las acciones que más han ayudado a las empresas a salir al exterior ha sido la iniciativa Foro de Marcas Renombradas que siempre ha contado con el apoyo incondicional de la Corona. Se trata de un ejemplo más ${ }^{36}$ de colaboración público-privada en la que el respaldo del Estado ha sido básico para su éxito. En definitiva, un nuevo ejemplo de diplomacia pública P-t-P que busca mejorar la imagen de España en el exterior

De nuevo vemos como la Casa Real, a través de sus miembros, ha ejercido de embajadores llegando allí donde Ministros y Presidentes no podía llegar, ya fuera por motivos políticos,

\section{Fruto de los} esfuerzos de diplomacia pública llevados a cabo por los diferentes gobiemos, España ha alcanzado importantes avances en la internacionalización economía 
ideológicos o simplemente electorales (Prego, 2000). Mención especial merece el Rey Felipe VI que en su condición de Príncipe de Asturias se convirtió en el mejor Embajador Económico de España. En los últimos años como Príncipe, Don Felipe centró su actividad en el apoyo a los emprendedores, a la internacionalización ${ }^{37}$, a la tecnología y la alta cualificación. En su Discurso de Proclamación, el Rey Felipe VI volvió a marcar como fundamentales para el futuro de España la tecnología, la educación y la internacionalización ${ }^{38}$ de la economía.

\section{c) España como una sociedad tolerante, culta y solidaria.}

En tercer y último lugar, España se ha esforzado por proyectarse como una sociedad tolerante, comprometida con la cultura y fuertemente solidaria. Si en las acciones anteriores eran Juan Carlos I y Felipe VI los actores más activos, en este punto ha sido la reina Sofía quien ha desarrollado una actividad más intensa. Aunque se trata de una actividad ajena al mundo político y económico, las consecuencias de estas acciones son económicas y en menor medida políticas. En otras palabras, la identificación de España con una sociedad tolerante, culta y solidaria tiene consecuencias directas tanto en su peso político internacional como en la atracción de inversiones o en la concesión de proyectos internacionales a nuestras empresas ${ }^{39}$. Por ello, la diplomacia pública española ha tratado de promover una imagen de España tolerante, culta y solidaria.

Por esta razón, los órganos centrales de la diplomacia han llevado a cabo un importante esfuerzo por mostrar a España como ejemplo de tolerancia de las tres religiones (cristiana, musulmana y judía) monoteístas. Prueba de ello es la constitución de las ya mencionadas Casa Árabe y Casa Sefarad que como afirma Carolina Sheinfeld (Sheinfeld, 2012) fueron construidas para desarrollar y fortalecer vínculos con regiones y países de interés para España. En lo que a otros niveles de la administración se refiere, destaca la Fundación Tres Culturas del Mediterráneo ${ }^{40}$, una institución que pretende ser puente de entendimiento entre las diferentes religiones del Mediterráneo ${ }^{41}$. El objetivo final de todas estas iniciativa es mejorar la imagen de España frente a otras culturas y religiones.

La buena imagen de la que España goza en Oriente Medio sirvió para acoger las Conversaciones de Paz de Madrid entre árabes e israelíes que marcaron el comienzo del Proceso de Paz. Estas negociaciones pusieron las bases de los Acuerdos de Oslo que permitieron alcanzar la paz entre israelíes y palestinos. Como colofón a este proceso que se inició en Madrid, Isaac Rabin y Yasir Arafat recibieron el Premio Príncipe de Asturias de Cooperación Internacioanl y el Premio Nobel de la Paz. De nuevo, vemos como la combinación de diferetnes acciones de diplomacia pública (G-t-P y P-t-P) tienen un efecto directo en la imagen de España en el exterior.

Probablemente la iniciativa más ambiciosa de toda la historia de la diplomacia (pública) española se llama "Alianza de Civilizaciones". Se trata de una propuesta hispano-turca de la que forman

37 "El Príncipe pide más presencia de empresas en el exterior frente a la crisis" (Expansión, 2012)

38 "Tenemos ante nosotros el gran desafío de impulsar las nuevas tecnologías, la ciencia y la investigación, que son hoy las verdaderas energías creadoras de riqueza" Disponible en

http://www.abc.es/casa-del-Rey/proclamacion/20140619/abci-discurso-integro-felipe-tras-201406191151.html

39 "los países se han dado cuenta de que un buen posicionamiento de su marca contribuye a atraer más turistas, incrementar las exportaciones y la inversión directa incluso a atraer el talento" (MAEC 2012, p. 256).

40 La Fundación Tres Culturas es un ejemplo de diplomacia pública. Siguiendo el modelo británico, la Junta de Andalucía reunió al Rey de Marruecos y al Centro Peres como ejemplo de tolerancia y diálogo de las tres religiones monoteístas. Su sede está en Sevilla.

41 una fundación que depende de la Junta de Andalucía con el apoyo del Rey de Marruecos, del Centro Peres de Israel y la Autoridad Nacional Palestina
Los órganos centrales de la diplomacia han llevado a cabo un importante esfuerzo por mostrar a España como ejemplo de tolerancia de las tres religiones monoteístas 
parte ya más de 90 países y 17 organizaciones internacionales. Como objetivo principal de la Alianza de Civilizaciones está la búsqueda y promoción del entendimiento entre las diferentes civilizaciones $^{42}$. Fruto de esta iniciativa se han desarrollado foros de diálogo y tolerancia que han potenciado la imagen de España como puente de entendimiento entre diferentes culturas y religiones.

En lo que se refiere a la aportación de la Casa Real, el Rey Juan Carlos ha trabajado intensamente en esta dirección durante sus 39 años de reinado. Sin embargo, el compromiso del Rey Felipe VI no es menor, lo que nos permite demostrar de nuevo la valía de la institución monárquica en la diplomacia pública. De hecho, el Rey Felipe VI ha enfatizado este rasgo identitario de nuestro país en su Discurso de Proclamación al señalar que "en España han convivido históricamente tradiciones y culturas diversas con las que de continuo se han enriquecido todos sus pueblos ${ }^{43}$ ". Sin lugar a dudas, vemos de nuevo como el continuismo de la Corona permite mantener cierta coherencia en aspectos básicos de la política exterior.

Como consecuencia de esta convicción, cabe destacar el apoyo a iniciativas multilaterales similares a la Alianza de Civilización. Este sería el caso de la Conferencia Euro-Mediterránea, del Diálogo Mediterráneo de la OTAN o del diálogo 5+5. Mención especial merece el Proceso de Barcelona donde se hablaba expresamente de "acercar a los dos lados del Mediterráneo y promover su conocimiento mutuo y mejorar las percepciones recíprocas” (Noya, 2007). En todos estos casos España ha jugado un rol protagonista ejerciendo un papel de mediador y facilitador del entendimiento entre los pueblos.

En todas estas iniciativas ha sido de vital importancia la amistad personal del Rey Juan Carlos I con mandatarios árabes, que unido a la imagen de una España tolerante, ha permitido la concesión del AVE del Desierto o la elección de España como miembro no permanente en el Consejo de Seguridad de Naciones Unidas (2002).

El ámbito de la cultura ha sido otro de los puntos que se han querido resaltar como propios de la imagen de España. Dentro de la diplomacia pública P-t-P hay que hacer mención especial a los Premio Cervantes y Príncipe de Asturias de las Letras y de las Artes. La mera existencia de estos galardones son muestran de un compromiso con la cultura del que la Corona es testigo de excepción. Su condición de actor no politizado dota de credibilidad a estas acciones que si bien están centradas en el campo de la cultura tienen consecuencias económicas y políticas. Como hemos anticipado anteriormente, la reina Sofía ha sido especialmente activa en este campo mostrando una sensibilidad especial con la cultura, y particularmente con la música y la danza. La identificación entre Corona y España ha permitido que el cariño mostrado por los miembros de la Casa Real con la cultura sirva para construir una imagen de España comprometida con la misma.

El campo de la solidaridad y la cooperación internacional es de gran importancia para España. Para demostrarlo vamos a fijarnos en dos hechos. El primero, el cambio de denominación del Ministerio de Asuntos Exteriores que desde ya algunos años ha añadido la palabra cooperación para denominarse MAEC. El segundo elemento es el reconocimiento dentro del documento

\section{El ámbito de la} cultura ha sido otro de los puntos que se han querido resaltar como propios de la imagen de España

42 En 1991 se organizaron en Madrid conversaciones entre Árabes e Israelíes. Estas reuniones se conocieron como el Proceso de Paz de Madrid

43 Discurso disponible en http://www.abc.es/casa-del-Rey/proclamacion/20140619/abci-discurso-integro-felipe-tras-201406191151.html 
del Real Instituto Elcano de dos objetivos estratégicos relacionados con este tema ${ }^{44}$. En el campo de la solidaridad debe ser destacada, de nuevo, la estrecha colaboración de la reina Sofía con la AECID. Como se muestra en el Anexo 1 la reina Sofía ha realizado innumerables "viajes de cooperación" a diversos países en vías de desarrollo para resaltar la imagen solidaria de España. No debemos olvidar que éste es un aspecto fundamental en la imagen del Estado ya que al igual que ocurría con la cuestión de la democracia, España también necesitaba cambiar su percepción internacional. Hasta 1982 era un país oficialmente en vías de desarrollo y desde entonces es un donante por lo que España desea aparecer como un país que habiendo sido estado en vías de desarrollo ahora es promotor de cooperación internacional.

Por último y dentro de la diplomacia pública P-t-P cabe destacar la existencia de un Premio Príncipe de Asturias de Cooperación Internacional. Se trata de un galardón que reconoce la faceta solidaria de personas e instituciones que muestra el compromiso de España con la cooperación al desarrollo. Cabe destacar que ese elemento de no-politización de la Corona dota de credibilidad a las políticas de cooperación al desarrollo que se antojan como fundamentales para conformar la imagen solidaria de España.

\section{Conclusiones}

A modo de conclusión, podemos afirmar que las tres características de la Corona que hemos señalado a comienzo del artículo (neutralidad política, continuidad institucional e identificación con España) hacen de esta institución en general, y de la figura del Jefe del Estado en particular, un actor fundamental para la diplomacia española.

Dentro de lo que hemos denominado diplomacia tradicional, la labor del Rey ha sido fundamental, tanto en las funciones atribuidas por la Constitución como en aquellas más discrecionales. A esto, hay que añadir las habilidades personales del Rey Juan Carlos I que sin duda han contribuido a que España ocupe un lugar destacado en la sociedad internacional. Ejemplos pueden ser la posición privilegiada de España en el Mundo Árabe o en Iberoamérica, donde las Cumbres Iberoamericanas se han mostrado como un instrumento muy valioso. En todo caso, dentro de la categoría de la diplomacia tradicional las relaciones Estado a Estado (G-t-G) siguen siendo fundamentales y, en este punto, la figura del Jefe del Estado sigue siendo imprescindible. En el caso de la Jefatura del Estado de España las características de nopolitización, continuismo e identificación con el Estado aportan un valor extra a esta institución lo que permite alcanzar logros que para otros órganos centrales es imposible

En la diplomacia no tradicional, y sobre todo en lo que a diplomacia pública se refiere, la labor de la Corona ha sido también muy relevante. De hecho, podemos afirmar que el Rey Juan Carlos I y la Reina Sofía ya practicaban la diplomacia pública a comienzos de los años 70, pues eran la cara más amable de una España no democrática. Posteriormente, la incorporación de Felipe VI a las labores de diplomacia pública ha sido esencial en el cambio de la imagen de España. De ser un Estado aislado, autoritario, atrasado económica y socialmente, España se ha convertido en una de las referencias de la modernidad en Occidente. En mi opinión, las tres
De ser un Estado aislado, autoritario, atrasado económica y socialmente, España se ha convertido en una de las referencias de la modernidad en Occidente

44 Objetivo 5.b "Cooperación al progreso socioeconómico e institucional de los países en desarrollo con énfasis en la reducción de la pobreza y las desigualdades por razones económicas, raciones o género". Objetivo 5.c "Ayuda humanitaria en casos de catástrofe o conflictos internacionales" (Molina, 2014, p, 62). 
caracterísitcas señaladas en este artículo como propias de la Corona han sido fundamentales en ese cambio que podría resumirse en:

a) Democratización de España y compromiso con los derechos humanos.

b) Modernización económica y social.

c) Promoción de España como una sociedad culta, solidaria y tolerante.

Para concluir, hay que reconocer el papel ejercido por la Corona en la diplomacia tradicional y pública. La credibilidad de la Corona ha sido fundamental para que el mensaje sea percibido como creible por el público al que va destinado. Estos aspectos hacen que ésta se convierta en un actor sin intereses particulares, que tiene una vocación de perdurar en el tiempo, lo que a largo plazo le convierte en actor mucho más eficaz que otros a la hora de aplicar la política exterior.

\section{Bibliografía}

Ayllon, L. (2014, 3 de junio). El Rey abdica. Don Juan Carlos motor de las relaciones con los países iberoamericanos. $A B C$

Álvarez, Ma I. (2014). Lecciones de Derecho Constitucional. Valencia: Tirant Lo Blanc.

Berridge, G.R. (2010). Diplomacy. Theory and Practice. Basingstoke: McMillan/Palgrave.

Bonney, N. (2010). The monarchy, the state and religion: Modernising the relationships. Political Quarterly, 81(2), 199-204

Canosa Usera, R. (2012). La Monarquía en las Constituciones de 1812 y 1978. Actualidad Jurídica (1578-956X), (31), 7-12.

Fuente Lafuente, C. (2006). Protocolo Oficial del Estado. Las Instituciones españolas del Estado y su ceremonial. Madrid: Ediciones Protocolo.

Gallego-Díaz, S. (1976, 3 de junio). El despertar del Rey en EE.UU. El País.

Garcia, D., \& Pacheco, R. (2014). Contemporary Spanish Foreign Policy. Abingdon: Routledge.

Gómez Mampaso, V., \& Sáenz de Santamaría, B. (2001). Una aproximación a las historia de las relaciones diplomáticas. Madrid: Universidad Pontificia Comillas.

Kane, J., Patapan, H. \& Hart, P. (2009). Dispersed Democratic Leadership: Origins, Dynamics, and Implications. Oxford: Oxford University Press Online.

Hamid, S. (2011, 8 de marzo). Why Middle East Monarchies might hold on. The Atlantic.

Lafuente, C. (2006). Protocolo Oficial del Estado. Las Instituciones españolas del Estado y su ceremonial. Madrid: Ediciones Protocolo.

Leon, C. (2011). Sociopolitical aspects of the Norwegian Monarchy. Bulletin of the Transylvania University of Brasov, Series IV: Philology \& Cultural Studies, 4, 97-104.

López Caballero, B. (2006). La Diplomacia y su protocolo. Madrid: Ediciones Protocolo.

McBain, G. (2012). Modernising the Monarchy--in legal terms: Part 3. King's Law Journal, 23(1), 69-93.
La credibilidad de la Corona ha sido fundamental para que el mensaje sea percibido como creíble por el público al que va destinado 
Mannheim J. (1994). Strategic Public Diplomacy \& American Foreign Policy. Oxford: Oxford University Press.

Mellisen, J. (Ed.) (2005). The New Public Diplomacy. Soft Power in International Relations. Basingstoke: Palgrave.

Mihle, A. (2013). The British and Danish Monarchies' awards of royal warrants in relation to EU state aid law and the free movement of goods. Croatian Yearbook of European Law $E$ Policy, 9, 177-217.

Molina, I. (coord.). (2014). Hacia una renovación estratégica de la política exterior española. Real Instituto Elcano: Madrid.

Molina, I., y Rodrigo, F. (2002). Las Transformaciones organizativas de la política exterior española. Revista de Estudios Políticos, Núm. 117. Julio-Septiembre, 173-220.

Noya, J. (2007). Diplomacia Pública para el Siglo XXI. Barcelona: Real Instituto Elcano:

d'Oliveira, H. U. J. (2012). The EU and its monarchies: Influences and frictions. European Constitutional Law Review, 8(1), 63-81

Pérez, C., y Abellén, L. (2014, 2 de junio). Un pilar de la integración europea. El País

Pérez de Cuellar, Javier. (1997). Manual de Derecho Diplomático. México D.F: Fondo de Cultura Económica.

Prego, Vi. (2000). Presidentes. Barcelona: Plaza y Janes.

Priego, A, \& Corral, C. (2005). Discurso de Benedicto XVI al cuerpo diplomático acreditado ante la santa sede, 10 de enero de 2005. Unisci Discussion Papers, (8), 1-6

Roobol, W. (2011). Twilight of the European Monarchy. European Constitutional Law Review, $7(2), 272-286$.

Rupérez, J. (2014, 3 de junio). El mejor embajador de España. ABC.

Schaub, D. (2002). Can liberal education survive liberal democracy? Public Interest, (147), 45.

Stepan, A., Linz, J. J., \& Minoves, J. F. (2014). Democratic parliamentary monarchies. Journal of Democracy, 25(2), 35-51.

Tuch, H. (1990). Communicating with the World: US Public Diplomacy Overseas. New York: St. Martin.

Turner, B. (2012). In Defence of Monarchy. Springer Science E Business Society, 49, 84-89.

MAEC (2012). Retos de nuestra acción exterior: Diplomacia Pública y Marca España (Colección Escuela Diplomática 18) Madrid: Escuela Diplomática.

Veuger, S. (2014, 6th June). The Fall ok Spain's King Juan Carlos I. The National Interest.

Vilariño, Eduardo. (2007). Curso de Derecho Diplomático y Consular. Madrid: Tecnos. 


\section{Anexo 1. Viajes diplomáticos realizados por la Casa Real entre enero de 2004 y junio de 2014}

Tabla 1. Viajes del Rey Juan Carlos I (2004-2014)

\begin{tabular}{|c|c|c|c|}
\hline Viaje & Fecha & Lugar & Motivo \\
\hline Oficial & 17/19-5-2014 & Arabia Saudita & Gira por los países del Consejo de Cooperación del Golfo. \\
\hline Oficial & $1 / 2-5-204$ & Bahréin & Gira por los países del Consejo de Cooperación del Golfo. \\
\hline Oficial & 29/30-4-2014 & Omán & \\
\hline Oficial & $15-4-2014$ & Kuwait & \\
\hline \multirow[t]{2}{*}{ Oficial } & 13-4-2014 & E.A.U & \\
\hline & $11-2-2014$ & $\begin{array}{l}\text { Lisboa } \\
\text { Portugal }\end{array}$ & Clausura del IX Encuentro COTEC Europa \\
\hline Oficial & $15-07-2013$ & $\begin{array}{l}\text { Rabat } \\
\text { Marruecos }\end{array}$ & \\
\hline Oficial & 24/27-10-2012 & India & \\
\hline Trabajo & 18/19-7-2012 & Rusia & \\
\hline Trabajo & 6-6-2012 & Chile & \\
\hline Trabajo & 3/4-6-2012 & Brasil & \\
\hline \multirow[t]{6}{*}{ Trabajo } & 4-4-2012 & Kuwait & \\
\hline & 29-3-2012 & $\begin{array}{l}\text { Bosnia y } \\
\text { Herzegovina }\end{array}$ & $\begin{array}{c}\text { Inauguración de la Plaza de España en Móstar en honor al Ejército } \\
\text { Español }\end{array}$ \\
\hline & 21/23-10-2011 & Jordania & Viaje de S.M. el Rey a Jordania \\
\hline & 13-10-2011 & Italia & Clausura del IX Encuentro COTEC Europa \\
\hline & 7-4-2011 & Berlín Alemania & Celebración del VI Foro Hispano-Alemán \\
\hline & 26/27-02-2011 & Kuwait & $\begin{array}{c}50^{\circ} \text { Aniversario de la Independencia, } 20^{\circ} \text { Aniversario de la Liberación } \\
\text { y } 5^{\circ} \text { Aniversario del Emir Sabah Al-Ahmad Al-Jaber Al Sabah }\end{array}$ \\
\hline \multirow[t]{2}{*}{ Privado } & $14-11-2010$ & $\begin{array}{l}\text { Kuwait, Qatar, } \\
\text { EAU }\end{array}$ & \\
\hline & $17-2-2010$ & $\begin{array}{l}\text { Washington } \\
\text { EEUU }\end{array}$ & $\begin{array}{c}\text { Acompañado por el Ministro Miguel Ángel Moratinos y por el Jefe de } \\
\text { la Casa de S.M. Alberto Aza }\end{array}$ \\
\hline Oficial & 8/9-2-2010 & Líbano & $\begin{array}{l}\text { Acompañado por el Ministro de Asuntos Exteriores M.A. Moratinos y } \\
\text { la Ministra C. Chacón }\end{array}$ \\
\hline Oficial & 25/26-11-2009 & Malta & $\begin{array}{l}\text { Acompañado por Ministro de Política Territorial, M. Chaves, el } \\
\text { alcalde de Madrid, A. Ruiz-Gallardón, y el jefe de Estado Mayor de la } \\
\text { Defensa, Gral. J. J. Rodríguez Fernández. }\end{array}$ \\
\hline Oficial & 23/24-1-2009 & Libia & \\
\hline Oficial & 19-6-2008 & $\begin{array}{l}\text { Moscú } \\
\text { Rusia }\end{array}$ & $\begin{array}{c}\text { Acompañado por el Secretario de Estado de Exteriores, A. Lossada } \\
\text { Torres-Quevedo }\end{array}$ \\
\hline Oficial & 3/4-6-2008 & Berlín & \\
\hline \multirow[t]{2}{*}{ Oficial } & 24/28-8-2008 & $\begin{array}{l}\text { EAU, A.Saudí y } \\
\text { Kuwait }\end{array}$ & $\begin{array}{c}\text { Delegación española organizada por la Confederación Española de } \\
\text { Organizaciones Empresariales, el Instituto Español de Comercio } \\
\text { Exterior y el Consejo Superior de Cámaras de Comercio }\end{array}$ \\
\hline & $31-12-2007$ & Afganistán & $\begin{array}{l}\text { Visita al Contingente Español en Afganistán, junto con el Ministro de } \\
\text { Defensa J.A. Alonso y Junta de Jefes del Estado Mayor. }\end{array}$ \\
\hline Trabajo & $6 / 7-2-2007$ & $\begin{array}{l}\text { Berlín y Múnich } \\
\text { Alemania }\end{array}$ & Clausura del Foro Hispano Alemán \\
\hline \multirow[t]{2}{*}{ Estado } & 6/8-11-2006 & Paraguay & \\
\hline & $6-4-2005$ & $\begin{array}{l}\text { Bruselas } \\
\text { Bélgica }\end{array}$ & Visita al Parlamento Europeo y la Comisión Europeo \\
\hline
\end{tabular}

FUENTE: Elaboración propia tomando datos de La Casa Real 
Tabla 2. Viajes de los Reyes Juan Carlos I y Sofía de Grecia (2004-2014)

\begin{tabular}{|c|c|c|c|}
\hline Viaje & Fecha & Lugar & Motivo \\
\hline Otro & $26 / 28-4-2014$ & $\begin{array}{l}\text { Roma } \\
\text { Italia }\end{array}$ & $\begin{array}{l}\text { Canonización de Sus Santidades los Papas Juan XXIII y Juan } \\
\text { Pablo II }\end{array}$ \\
\hline \multirow[t]{2}{*}{ Estado } & $13-5-2011$ & Suiza & \\
\hline & $24 / 25-2011$ & Rusia & Inauguración Año Dual España-Rusia \\
\hline Oficial & $30-11-2009$ & Madeira Portugal & Visita a la Región Autónoma de Madeira \\
\hline Estado & 24/26-6-2009 & Australia & $\begin{array}{l}\text { Acompañados por la Ministra de Ciencia e Innovación, Cristina } \\
\text { Garmendia }\end{array}$ \\
\hline Estado & 22/24-06-2009 & Nueva Zelanda & \\
\hline Estado & $7-5-2009$ & $\begin{array}{l}\text { Estonia, Letonia y } \\
\text { Lituania }\end{array}$ & \\
\hline Otro & $18 / 20-2-2009$ & Pensacola EEUU & Celebración del 450 aniversario de la Base de Pensacola \\
\hline Estado & $17 / 18-2-2009$ & Jamaica & \\
\hline Estado & $16 / 17-2009$ & Trinidad y Tobago & \\
\hline Estado & 8/14-11-2008 & Japón & $\begin{array}{l}\text { Acompañados por la Ministra Cristina Garmendia y por los } \\
\text { Secretarios de Estado Ángel Lossada y Silvia Iranzo }\end{array}$ \\
\hline Estado & 27/28-10-2008 & Perú & \\
\hline \multirow[t]{2}{*}{ Estado } & $4 / 6-2-2008$ & Egipto & \\
\hline & $21-11-2007$ & Viena & Visita a la OSCE e inauguración de la nueva sede. \\
\hline Oficial & 29/30-6-2007 & Kazajstán & \\
\hline Estado & 24/29-6-2007 & R.P. China & $\begin{array}{l}\text { Acompañado por el Ministro de Industria J. Clos y por el Ministro } \\
\text { de Asuntos Exteriores M.A. Moratinos }\end{array}$ \\
\hline Estado & 29/31-5-2007 & Hungría & $\begin{array}{l}\text { Acompañado por el Ministro de Asuntos Exteriores M.A. } \\
\text { Moratinos }\end{array}$ \\
\hline Estado & 16/18-4-2007 & Luxemburgo & \\
\hline Estado & 29/30-3-2007 & Guatemala & \\
\hline Estado & $27 / 28-3 / 2007$ & El Salvador & \\
\hline Estado & 23/26-3-2007 & Colombia & $\begin{array}{l}\text { Acompañados por el Ministro de Asuntos Exteriores, M.A. } \\
\text { Moratinos, y la secretaria de Estado para lberoamérica, T. } \\
\text { Jiménez. }\end{array}$ \\
\hline Estado & $13 / 15-3-2007$ & Argelia & \\
\hline Estado & 6/8-6-2006 & Noruega & \\
\hline Oficial & $26 / 27-4-2006$ & Qatar & \\
\hline Estado & $24 / 26-4-2006$ & Jordania & $\begin{array}{l}\text { Acompañado por el Ministro de Asuntos Exteriores M.A. } \\
\text { Moratinos }\end{array}$ \\
\hline Oficial & $8 / 10-4-2006$ & Arabia Saudí & \\
\hline Estado & 27/29-3-2006 & Francia & \\
\hline Estado & $21 / 24-2-2006$ & Tailandia & \\
\hline \multirow[t]{2}{*}{ Estado } & $18 / 21-2-2006$ & Vietnam & \\
\hline & 7/8-4-2004 & Vaticano & Solemne funeral por S.S. el Papa Juan Pablo II \\
\hline Oficial & 6/8-3-2005 & $\begin{array}{l}\text { Ginebra } \\
\text { Suiza }\end{array}$ & Visita a las oficinas de las Naciones Unidas \\
\hline Estado & 18/19-1-2004 & Marruecos & \\
\hline
\end{tabular}




\begin{tabular}{|l|l|l|l|}
\hline Oficial & $21 / 24-11-2004$ & $\begin{array}{l}\text { Seattle, Crawford } \\
\text { EEUU }\end{array}$ & \\
\hline Oficial & $18 / 19-11-2004$ & $\begin{array}{l}\text { Cartagena de Indias } \\
\text { Colombia }\end{array}$ & \\
\hline Oficial & $16 / 17-11-2004$ & Argentina & III Congreso Internacional de la Lengua Española \\
\hline Estado & $13 / 18-01-2004$ & Chile & \\
\hline
\end{tabular}

FUENTE: Elaboración propia tomando datos de La Casa Real

Tabla 3. Viajes realizados por Reina Sofía (2004-2014)

\begin{tabular}{|c|c|c|c|}
\hline Viaje & Fecha & Lugar & Motivo \\
\hline Solidaridad & $3 / 4-6-2014$ & $\begin{array}{l}\text { Nueva York } \\
\text { EEUU }\end{array}$ & Recogida del Premio "Path to Peace" \\
\hline Cooperación & $18-3-2014$ & Guatemala & Viaje de Cooperación \\
\hline Cooperación & $8 / 11-4-2013$ & Mozambique & Viaje de Cooperación \\
\hline Cooperación & $15 / 19-10-2012$ & Bolivia & Viaje de Cooperación \\
\hline Cooperación & $1 / 7-7-2012$ & Filipinas & Viaje de Cooperación \\
\hline Cooperación & $7-10-2011$ & Haití & Viaje de Cooperación \\
\hline Privado & $23 / 25-3-2011$ & Grecia & \\
\hline Cooperación & $18-3-2011$ & $\begin{array}{l}\text { Colombia y } \\
\text { Ecuador }\end{array}$ & Viaje de Cooperación \\
\hline Oficial & $17 / 19-11-2010$ & EEUU & $\begin{array}{l}\text { Inauguración de la exposición "Balenciaga" y entrega de la Gold } \\
\text { Medal". Almuerzo y Conferencia organizado por el Queen Sofia } \\
\text { Spanish Institute }\end{array}$ \\
\hline Cooperación & $8 / 9-4-2010$ & Etiopía & Viaje de Cooperación \\
\hline Oficial & $7 / 8-4-2010$ & Kenia & Cumbre regional del Microcrédito para África y Oriente Medio \\
\hline Oficial & $10 / 12-3-2010$ & Chipre & \\
\hline Otro & $7-10-2009$ & Atenas & Visita al nuevo museo de la Aerópolis \\
\hline Oficial & $5 / 8-10-2009$ & Grecia & \\
\hline Cooperación & $1 / 22-01-2009$ & $\begin{array}{l}\text { Rep. } \\
\text { Dominicana y } \\
\text { Haití }\end{array}$ & Viaje de Cooperación \\
\hline Oficial & 16/18-12-2008 & $\begin{array}{l}\text { Damasco } \\
\text { Siria }\end{array}$ & $\begin{array}{l}\text { Asistencia a los actos del Día de España dentro del Programa } \\
\text { "Damasco Capital Cultural del Mundo Árabe" }\end{array}$ \\
\hline Oficial & $14 / 17-5-2008$ & Grecia & Inauguración de la Casa de la Lengua en Rodas. \\
\hline Cooperación & $18 / 23-2-2008$ & Camboya & $\begin{array}{l}\text { Viaje de Cooperación acompañada por el Director de la AECID Juan } \\
\text { Pablo de la Iglesia }\end{array}$ \\
\hline Otro & $15 / 18-10-2007$ & Grecia & \\
\hline Otro & $4 / 5-10-2007$ & El Salvador & \\
\hline Cooperación & $5 / 7-2-2007$ & $\begin{array}{l}\text { Indonesia y } \\
\text { Camboya }\end{array}$ & Suspendido el viaje a Camboya por causa familiar \\
\hline Oficial & $10-12-2006$ & $\begin{array}{l}\text { Oslo } \\
\text { Noruega }\end{array}$ & Ceremonia de entrega del Premio Nobel de la Paz a Mohammed Yunus \\
\hline Otro & $11-11-2006$ & Canadá & Asistencia a la Cumbre Mundial del Microcrédito \\
\hline Oficial & $11 / 14-06-2006$ & Tailandia & $60^{\circ}$ aniversario de la entronización de S.M. el Rey Bhumibol Adulyadej \\
\hline Cooperación & $2 / 5-4-2006$ & $\begin{array}{l}\text { Senegal y Cabo } \\
\text { Verde }\end{array}$ & Viaje de Cooperación \\
\hline
\end{tabular}




\begin{tabular}{|l|l|l|l|}
\hline Otro & $18 / 19-10-2005$ & $\begin{array}{l}\text { Guatemala y El } \\
\text { Salvador }\end{array}$ & Visita con motivo de las inundaciones producidas por la tormenta Stan \\
\hline Otro & $27-4-2005$ & Colombia & IV Foro Internacional del Microcrédito \\
\hline Otro & $25-4-2005$ & México & Foro sobre Microfinanzas y Desarrollo \\
\hline Otro & $18 / 20-4-2005$ & Chile & Cumbre Regional de Microcrédito para América Latina y el Caribe \\
\hline Cooperación & $21 / 25-2-2005$ & $\begin{array}{l}\text { Argelia, } \\
\text { Mauritania y } \\
\text { Marruecos }\end{array}$ & Viaje de Cooperación \\
\hline Otro & $27-5-2004$ & Jordania & $\begin{array}{l}\text { Visita junto a SS.AA.RR los Príncipes de Asturias al Príncipe Hussein y } \\
\text { a la Princesa Noor Hamzah }\end{array}$ \\
\hline
\end{tabular}

FUENTE: Elaboración propia tomando datos de La Casa Real

Tabla 4. Viajes del Rey Felipe VI en su condición de Príncipe de Asturias (2004-2014)

\begin{tabular}{|c|c|c|c|}
\hline Viaje & Fecha & Lugar & Motivo \\
\hline Cortesía & 7/9-5-2014 & Costa Rica & $\begin{array}{l}\text { Habilitado mediante el Real Decreto 289/2014 para asistir a la toma de } \\
\text { posesión del Presidente electo, Excmo. Sr. Luis Guillermo Solís }\end{array}$ \\
\hline Cortesía & $\begin{array}{l}31-5-2014 \\
1-6-2014\end{array}$ & El Salvador & $\begin{array}{l}\text { Habilitado por el Rey Juan Carlos I para representar a España en la } \\
\text { ceremonia de investidura de Salvador Sánchez Cerén }\end{array}$ \\
\hline Otro & 13-3-2014 & Brasil & $\begin{array}{l}\text { Presentación de la Fundación Consejo España-Brasil. Acompañado del } \\
\text { Secretario de Estado de Cooperación e Iberoamérica Jesús Gracia }\end{array}$ \\
\hline Cortesía' & 10/11-3-2014 & $\begin{array}{l}\text { Santiago de } \\
\text { Chile }\end{array}$ & $\begin{array}{l}\text { Habilitado por el Rey Mediante el Real Decreto 98/2014 para } \\
\text { representar a España en la ceremonia de investidura de Michel Bachelet }\end{array}$ \\
\hline Cortesía & 7-2-2014 & Túnez & $\begin{array}{l}\text { Asistencia a la ceremonia de adopción de la nueva constitución } \\
\text { Acompañado por el Secretario de Estado Gonzalo de Benito }\end{array}$ \\
\hline Cortesía & 26/27-1-2014 & Honduras & $\begin{array}{l}\text { Asistencia a la Toma de posesión de Orlando Hernández. Designado } \\
\text { como representante de España por el Real Decreto 1018/2013, de } 20 \\
\text { de diciembre }\end{array}$ \\
\hline Oficial & 13/19-11-2013 & $\begin{array}{l}\text { California y } \\
\text { Florida } \\
\text { EEUU }\end{array}$ & $\begin{array}{l}\text { Acompañado por su S.A.R. la Princesa de Asturias y por el Ministro de } \\
\text { Asuntos Exteriores García-Margallo }\end{array}$ \\
\hline Oficial & 17/20-10-2013 & Panamá & $\begin{array}{l}\text { Cumbre Iberoamericana. Acompañado por el Ministros de Asuntos } \\
\text { Exteriores García-Margallo }\end{array}$ \\
\hline Cortesía & 14/15-8-2013 & Paraguay & $\begin{array}{l}\text { Asistencia a la Toma de posesión Horacio M. Cartes Jara. Acompañado } \\
\text { por el Secretario de Estado de Cooperación e lberoamérica Jesús Gracia }\end{array}$ \\
\hline Cortesía & $2325-5-2013$ & Ecuador & $\begin{array}{l}\text { Asistencia a la Toma de posesión de Rafael Correa. Designado como } \\
\text { representante de España mediante el Real Decreto 298/2013, de } 26 \text { de } \\
\text { abril }\end{array}$ \\
\hline Cortesía & $\begin{array}{l}29-11-2012 \\
1-12-2012\end{array}$ & México & $\begin{array}{l}\text { Asistencia a la Toma de posesión Peña Nieto. Designado como } \\
\text { representante de España mediante Real Decreto 1530/2012, de } 8 \text { de } \\
\text { noviembre. }\end{array}$ \\
\hline Oficial & $4 / 5-10-2012$ & Ecuador & Acompañado por S.A.R. la Princesa de Asturias \\
\hline Oficial & 2/4-10-2012 & Panamá & Acompañado por S.A.R. la Princesa de Asturias \\
\hline Cortesía & 15/18-8-2012 & $\begin{array}{l}\text { St. } \\
\text { Domingo R. } \\
\text { Dominicana }\end{array}$ & $\begin{array}{l}\text { Asistencia a la Toma de posesión Danilo Medina. Designado como } \\
\text { representante de España mediante Real Decreto 1083/2012, de } 13 \text { de } \\
\text { julio. }\end{array}$ \\
\hline Otro & 19/23-6-2012 & EEUU & Acompañado por S.A.R. la Princesa de Asturias \\
\hline Oficial & $\begin{array}{l}30-5-2012 \\
1-6-2012\end{array}$ & Portugal & $\begin{array}{l}\text { Acompañado por S.A.R. la Princesa de Asturias y por el Sec. de Estado } \\
\text { para la UE Méndez de Vigo }\end{array}$ \\
\hline Oficial & 21-3-2012 & Djibuti & $\begin{array}{l}\text { Visita a las tropas españolas desplegadas en la Operación Atalanta y a } \\
\text { la República de Djibuti }\end{array}$ \\
\hline Trabajo & $11 / 12-2-2012$ & Honduras & \\
\hline
\end{tabular}




\begin{tabular}{|c|c|c|c|}
\hline Cortesía & 10/11-1-2012 & Nicaragua & $\begin{array}{l}\text { Asistencia a la Toma de posesión Daniel Ortega. Designado como } \\
\text { representante de España mediante el Real Decreto 1890/2011, de } 30 \text { de } \\
\text { diciembre. Acompañado por el Sec. de Estado para lberoamérica Jesús } \\
\text { Gracia }\end{array}$ \\
\hline Cortesía & 9/11-12-2011 & Argentina & $\begin{array}{l}\text { Asistencia a la Toma de posesión Cristina Fernández. Designado como } \\
\text { representante de España mediante el Real Decreto mediante el Real } \\
\text { Decreto 1718/2011, de } 18 \text { de noviembre. }\end{array}$ \\
\hline Oficial & 21/25-11-2011 & Chile & \\
\hline Otro & $7-11-2011$ & $\begin{array}{l}\text { Londres } \\
\text { R. Unido }\end{array}$ & Acompañado por S.A.R. la Princesa de Asturias \\
\hline Otro & $26-10-2011$ & Arabia Saudí & \\
\hline Cortesía & 27/28-7-2011 & Perú & $\begin{array}{l}\text { Asistencia a la Toma de posesión de Ollanta Humala. Designado } \\
\text { como representante de España mediante el Real Decreto mediante el } \\
\text { mediante el Real Decreto 979/2011, de } 8 \text { de julio. Acompañado del Sec. } \\
\text { Estado de Asuntos Exteriores Yáñez-Barnuevo }\end{array}$ \\
\hline Oficial & $12 / 14-4-2011$ & Jordania & \\
\hline Otro & $12-4-2011$ & Palestina & \\
\hline Oficial & $11 / 12-4-2011$ & Israel & \\
\hline Cortesía & $1 / 2-1-2011$ & Brasil & $\begin{array}{l}\text { Asistencia a la Toma de posesión de Dilma Rousseff. Designado como } \\
\text { representante de España mediante el Real Decreto 1677/2010, de } 10 \text { de } \\
\text { diciembre. Acompañado del Sec. Estado de Asuntos Exteriores Yáñez- } \\
\text { Barnuevo }\end{array}$ \\
\hline Oficial & $22 / 25-11-2010$ & Perú & Acompañado por S.A.R. la Princesa de Asturias \\
\hline Cortesía & 6/8-8-2010 & Colombia & $\begin{array}{l}\text { Asistencia a la Toma de posesión de J.M. Santos. Acompañado del Sec. } \\
\text { Estado de Asuntos Exteriores e Iberoamérica Juan P. de la Iglesia }\end{array}$ \\
\hline Cortesía & $8-5-2010$ & Costa Rica & $\begin{array}{l}\text { Asistencia a la Toma de posesión de Laura Chinchilla. Acompañado del } \\
\text { Sec. Estado para Iberoamérica Juan P. de la Iglesia }\end{array}$ \\
\hline Cortesía & $10 / 11-3-2010$ & Chile & $\begin{array}{l}\text { Asistencia a la Toma de posesión de Sebastián Piñera. Designado como } \\
\text { representante de España mediante el Real Decreto 175/2010, de } 19 \text { de } \\
\text { febrero }\end{array}$ \\
\hline Cortesía & $1-3-2010$ & Uruguay & $\begin{array}{l}\text { Asistencia a la Toma de posesión de José Múijica. Designado como } \\
\text { representante de España mediante el Real Decreto 175/2010, de } \\
19 \text { de febrero Acompañado del Sec. Estado de Asuntos Exteriores e } \\
\text { Iberoamérica Juan P. de la Iglesia }\end{array}$ \\
\hline Cortesía & 21/23-1-2010 & Bolivia & Asistencia a la Toma de posesión de Evo Morales. \\
\hline Oficial & $16 / 19-1-2010$ & $\begin{array}{l}\text { Abu Dabi } \\
\text { EAU }\end{array}$ & Acompañado por S.A.R. la Princesa de Asturias \\
\hline Oficial & 9/12-11-2009 & India & Acompañado por S.A.R. la Princesa de Asturias \\
\hline Otro & $5 / 8-10-2009$ & EEUU & $\begin{array}{l}\text { Visita a los estados de Nuevo México e Illinois. } \\
\text { Acompañado por S.A.R. la Princesa de Asturias }\end{array}$ \\
\hline Oficial & 27/23-7-2009 & Rumanía & Acompañado por S.A.R. la Princesa de Asturias \\
\hline Cortesía & 1/2-6-2009 & Colombia & $\begin{array}{l}\text { Asistencia a la Toma de posesión de Mauricio Funes. Acompañado por } \\
\text { S.A.R. la Princesa de Asturias }\end{array}$ \\
\hline Oficial & 26/29-5-2009 & & Acompañado por S.A.R. la Princesa de Asturias \\
\hline Otra & 15/18-3-2009 & $\begin{array}{l}\text { Nueva York } \\
\text { EEUU }\end{array}$ & Acompañado por S.A.R. la Princesa de Asturias \\
\hline Otra & $7-11-2008$ & Líbano & Visita a las tropas españolas \\
\hline
\end{tabular}

1 Desde 1996 S.A.R el Príncipe Felipe asume la asistencia a las Ceremonias de Transmisión del Mando Presidencial de los Jefes de Estado Iberoamericanos. Desde entonces ha asistido a un total de 69 tomas de posesión. 